Article

\title{
Design for Six Sigma (DFSS) Applied to a New E-Segment Sedan
}

\section{Daniela Francia *, Giampiero Donnici® ${ }^{\circledR}$, Gian Marco Ricciardelli and Gian Maria Santi}

Department of Industrial Engineering, Alma Mater Studiorum University of Bologna, V.le Risorgimento, 2, 40136 Bologna, Italy; giampiero.donnici@unibo.it (G.D.); gian.ricciardelli@studio.unibo.it (G.M.R.); gianmaria.santi@studio.unibo.it (G.M.S.)

* Correspondence: d.francia@unibo.it

Received: 21 October 2019; Accepted: 25 December 2019; Published: 21 January 2020

\begin{abstract}
Innovation activities" means all the scientific, technological, organizational, financial and commercial steps aimed at implementing innovation. Some innovation activities are themselves innovative, others are not new, but they are necessary for the implementation of innovation, such as Research and Development not linked to a specific innovation. Innovation has a close reference to the economic market, that is to say with the users of the innovated product: if these are not sufficiently developed they are not able to understand it and appreciate it. Innovation, making the process better, generates greater competitiveness: it is the dream of something better that translates into general well-being. This work presents an innovative hybrid car's design, belonging to the E-segment. The choice of this segment is already innovative in its nature, as despite being currently in strong development, hybrid and electric engines are still little used for large sedans. The method we present in this paper for the car design is also innovative and is called Design for Six Sigma. It is a method used to develop new products, through the determination of customer and market needs and the transformation of these requests into the product generated.
\end{abstract}

Keywords: Design for Six Sigma; Quality Function Deployment; automotive; car; E-segment; sedan; Bench Marking

\section{Introduction}

The Design for Six Sigma consists of a design method for the development of new products that aims to better respect the demands and expectations of the customer. This research is based on products that already exist: the aim is to succeed in eliminating defects and contradictions found in the products on the market, so as to obtain a new product that is more satisfying and innovative.

Different approaches exist for the application of the method:

- $\quad$ DMADV; Define, Measure, Analyze, Design and Validate.

- CDDOV; Concept, Define, Design, Optimization and Verification phases.

- IDOV; Concept, Design, Optimize, Verify.

- IDDOV; Identify, Define, Develop, Optimize, Verify.

- $\quad$ RADIOV; Requirements, Architecture, Design, Integration, Optimization, Verification.

Although each approach follows its own guideline it is possible to identify some common steps. The basic activities that are carried out in a Design for Six Sigma approach are the following: investigation of customer requests and needs, analysis and classification of such requests, transformation of customer requests into engineering information, design development, verification performance, and implementation of processes in line with the objective to be achieved. Other design methods centered 
on the innovation enhancement are TRIZ and Design Thinking. TRIZ is the Russian acronym for the "Theory of Inventive Problem Solving," an international system of creativity developed in the U.S.S.R. between 1946 and 1985, by engineer and scientist Genrich S. Altshuller and his colleagues.

According to TRIZ, universal principles of creativity form the basis of innovation. TRIZ identifies and codifies these principles, and uses them to make the creative process more predictable.

TRIZ is most useful in roles such as product development, design engineering, and process management. For example, Six Sigma quality improvement processes often make use of TRIZ [1-7].

Design Thinking is a specific method to solve complex (wicked) problems and to generate innovative solutions, based on a user-centered approach with multi-disciplinary teams. Design thinking is becoming more and more popular among business schools, and it is applied in R and D departments of companies to foster innovation. Unlike the typical creative design process, which is usually an intuitive and individual process, design thinking consists of a flexible sequence of process steps and iteration loops, each including several tools and resulting in different artifacts. Since it is the idea of design thinking to be applied by multi-disciplinary teams instead of well-trained designers, an explicit understanding of the process is crucial [8].

Among scientific research and papers connected to the automotive industry, there may be specified few groups of issues examined from the perspective of life-cycle stage of an automobile including (i) development and manufacturing, (ii) use, and (iii) disposal (end-of-life).

The recent technology development has led to challenges in the use of vehicles and their disposal (e.g., in considerably reduction of vehicles life cycles). The shortening of product life cycle in the automotive industry has resulted in a growing number of vehicles at the last stage. On the basis of research experience, it was stated that the most challenging phase is end-of-life stage. This issue could be supported by design strategies, as Design for Disassembly (DfD), that help designers to take care of the disassembly of products in order to recycle, reuse, remanufacture, correct disposal [9-11].

In addition, car spare parts play a major role in business, maintenance and repairs due to the short-term orders realization and flexible services [12]. The predictive market gives the possibility of better assessment of trends by questionnaire surveys. This is the result of asking participants not only to perceive reality, but also to estimate probability of the event appearance on the market. Considering specific factors of disassembling business, in literature predictive market has been chosen as appropriate tool for demand for reusable parts forecasting [13].

Taking into account the significance of the disassembling facility, in the context of the company's activities, there was identified a need to support the decision-making process related to forecasting the demand for spare parts. However, these aspects are only secondary compared to the aim of these paper and they could be further explored in future works.

\section{Design for Six Sigma-DMADV}

The DMADV approach is the most used in the field of Design for Six Sigma and is the one that will be used for our analysis [14].

As previously mentioned, this approach consists of 5 distinct phases: Define, Measure, Analyze, Design, and Validate. Each phase has its own objective; at the end of the last phase it will have come to a design in line with the Design for Six Sigma methodology.

1. Define. During the first phase, information is collected on the client's requests and needs. Specifically, it is important to note what problems the customer encounters when approaching a specific product already on the market.

2. Measure. In this phase the Quality Function Deployment (QFD) analysis is carried out to translate the customer's needs into engineering information. In this way it is possible to obtain those characteristics linked to the design that influence the respect or not of the customer's requests.

3. Analyze. The key features obtained in the second phase are used to conceive the design of the new product. For this purpose, a benchmarking analysis is carried out, which allows to study similar designs of competitive models with the product in question. 
4. Design. Depending on the results obtained from the analysis phase, we proceed with the design using appropriate software of the new product. In this phase, all the information obtained from the previous points must be taken into consideration and attempts must be made to respect them to the best.

5. Validate. In this last phase, it is stated with certainty that the finished product confirms the expected results. It is possible to produce prototypes to be tested to ensure that the product is in line with the required characteristics.

All could be clearer through the image (Figure 1) below:

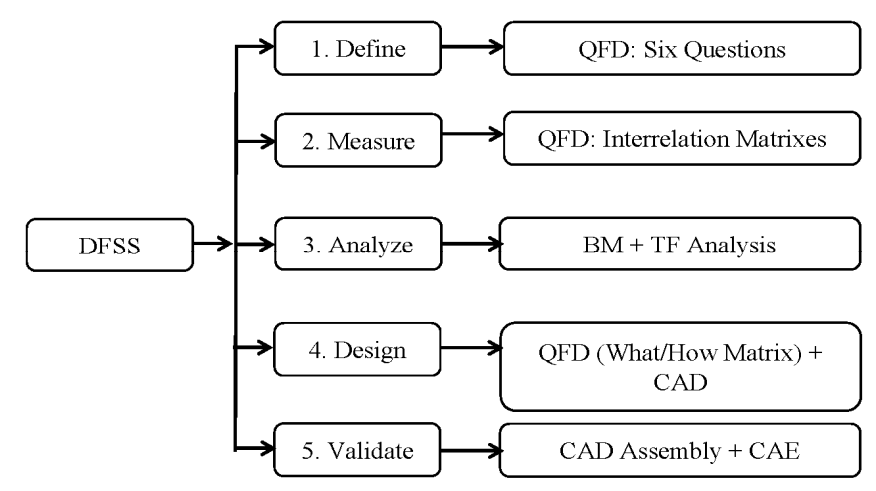

Figure 1. Design for Six Sigma (DFSS) Structure and Application.

\section{DFSS: DEFINE}

This phase involves the collection of information regarding the client's requests and needs.

More specifically, it is necessary to obtain data on which to rely in order to understand what the product requirements must be.

To this end, the use of the QFD as a tool for clarification of the task is useful. This method lends itself to the planning of each phase and therefore can be used at various levels. The method starts with the correct identification of product needs, an easily obtainable objective, interviewing a limited number of people. The questions to be answered are the following, collected in Table 1.

Table 1. QFD—Six Questions.

\begin{tabular}{ll}
\hline \multicolumn{1}{c}{ Six Questions } & \multicolumn{1}{c}{ Free Answers } \\
WHO uses/buys the product? & $\begin{array}{l}\text { The product is intended for the population groups that we could identify as the upper middle class. The car we are } \\
\text { going to design falls into the category of so-called Executive cars. The clientele is therefore mostly composed of } \\
\text { adult men over the age of } 40 \text { years old. } \\
\text { In addition, cars of this kind are also attractive as regards the company car or taxi-limousine market. }\end{array}$ \\
\hline WHAT are the uses of the product? & $\begin{array}{l}\text { The product by its very nature can be identified as a long-distance car, which is ideal for long journeys in comfort } \\
\text { and for transporting passengers equally comfortably and safely. The car could therefore easily perform the function } \\
\text { of a company machine, being suitable for long journeys, also allowing for a possible saving in consumption. }\end{array}$ \\
\hline WHERE is the product used? & $\begin{array}{l}\text { The product is mainly used outside built-up areas, given its large size and performance characteristics. Its features } \\
\text { make it the ideal product for long journeys on suburban roads and highways. } \\
\text { The introduction of the electric motor, however, allows a greater use also in the city, where traveling at low speeds } \\
\text { the electric motor would carry out much of the task minimizing consumption. }\end{array}$ \\
\hline WHEN is the product used? & $\begin{array}{l}\text { Its use is not subjected to seasonality and is almost unchanged throughout the year. Being a car of this type, its use } \\
\text { will be daily and frequent in most cases. }\end{array}$ \\
\hline WHY was it chosen? Why could it & $\begin{array}{l}\text { It guarantees good performance and safety, combined with high comfort and low consumption compared to cars in } \\
\text { the same segment. Being a hybrid vehicle, it allows you to save on fuel, road tax, insurance, and parking, also } \\
\text { allowing access to any LTZ. }\end{array}$ \\
\hline be chosen? & The product is used for long distances and for fast movements. \\
\hline HOW is the product used? &
\end{tabular}

This interview allows the data on the customer to be made explicit, up to a complete list of needs. The list will only contain qualitative data such as ideas, opinions, perceptions, and desires, so the classical methods of relationship between numbers cannot be used to treat similar data.

The tools that we are going to introduce later will allow us to treat qualitative data in the same way as numerical data, in order to be able to work on them, comparisons, and classifications. 
The objective is to elaborate the qualitative data obtained in order to arrive at the product specification.

To do this it is necessary to introduce the following tools:

- Affinity diagrams

- Interrelation matrices

- $\quad$ Relationship matrices

Through the affinity diagram, the qualitative information obtained previously is summarized and reclassified into general themes or fundamental ideas. In this way, it is possible to determine the logical groupings of the needs. The data are then collected in homogeneous groups, following the method proposed in [15], and appropriate titles are selected for the groups.

We therefore obtain a summary list of the customer's advanced requests:

PRICE: the purchase of hybrid vehicles in Italy is still very limited compared to the purchase of petrol or diesel cars. One of the reasons for this trend is the price that is usually higher than the equivalent models with petrol or diesel engines. Only in recent years has the hybrid become a more solid reality, even in Italy. "Since the beginning of 2018, there has been an increase of $33.1 \%$ compared to the same period of the previous year with over 55,000 vehicles registered equal to more than $80 \%$ of all those sold in the whole 2017". "The main reasons that are driving hybrid car sales in recent years are precisely the benefits offered to those who own hybrid or electric cars such as exemption from stamp duty, discounts on RC cars, the possibility of driving in Limited Traffic Zone (LTZ) and parking free in urban centers. Therefore, it is clear that the price of the car and the costs deriving from its use should be minimized as much as possible".

PERFORMANCE: "If, as is true, the performance aspect of hybrid cars is of concern to some motorists, the test numbers show that the performance of hybrid cars is, in principle, similar to those obtained by the corresponding models, with diesel or petrol engines". When it comes to a segment car from us in analysis, performance plays a fundamental role in the choice of the customer, who expects to have the advantages of a hybrid engine without having a decline in performance.

COMFORT: A customer who buys a car belonging to segment $\mathrm{E}$ expects to be able to make long journeys in comfort, both for those who drive and for passengers. What is required is adequate space in the passenger compartment, so that the car can comfortably accommodate 5 people. Furthermore, the stresses to which the car is subjected during the journey must be taken into consideration, which in turn affect the driver. In order to offer the maximum possible comfort, it will be necessary to insert the appropriate suspensions and equip the passenger compartment with good sound insulation so as to make the journey more silent.

CONSUMPTION: The purchase of a hybrid car is almost always dictated by the customer's desire to own a car with low fuel consumption. "Beyond the official values communicated by the manufacturers, consumption also fluctuates a lot depending on your driving style, as well as the type of use you make of the car itself. On urban roads, the differential with a single-fueled vehicle will be marked. Tapering as you leave the city and frequent extra-urban contexts. That said, the mixed consumption is always lower than that of an equivalent model exclusively for internal combustion."

LOADING CAPACITY: Anyone who buys a car of this type, even if it is not a station wagon, expects to have a spacious trunk available, which allows it to contain suitcases or other bulky items. The right compromise is therefore sought between elegance of design and load capacity, generally contrasting characteristics.

AESTHETICS/DESIGN: Without taking anything away from all the aspects that characterize a car and that guide its choice, the aesthetic aspect that is the car design, it is still one of the most important factors for its sale. It will therefore be necessary to give the car a sleek and elegant appearance.

ACCESSORIES: From a car in this segment, for which customers are willing to pay figures of around 50,000 euros or more, the accessories certainly do not pass into the background. When choosing a car, the presence or absence of specific, standard or paid options can make the difference. 


\section{DFSS: MEASURE}

A study of the items listed in the previous list is now necessary, more precisely we try to highlight any existing dependency relationships.

Evaluation matrixes can be used to estimate relative importance or independence relationships among requirements. The interrelation matrix is an instrument evaluating the relationships of dependency (first use) and/or of relative importance (second use) among various necessities or ideas; the instrument is used also to explain priorities and to establish the best arrangement of activities.

The dependence between the requirements can be none, weak, medium, or strong.

Instead, in the second practice, the matrix is employed to estimate relative importance among all the variables.

Through the matrix employment, it is easy to understand that the highest values of the sums per rows specify which is the most important variable among all of them (i.e., those which have more influence on the others).

All the matrixes have been formulated by investigating a thematic focus group that is composed by 20 people more or less, chosen among industrial experts, from different kinds of industrial reality, Professors and PhD students from University.

Finally, after explanation of the task, the conceptual design starts at first, followed by the constructive one $[1-7,16]$.

The interrelation matrices formulated in this paper provided us with the tools to create a unique ranking.

The first matrix we use is the dependency matrix. To build it, perform the following steps:

(1) We put all the items of the customer's product requirements, both in column and in line

(2) We determine the cause and effect relations, the question to ask then will be: the element on the line, how does it depend on the elements on the columns?

(3) We indicate by the use of numbers the dependency relation presents between the element in column and the one in line, distinguishing between: none dependence (0), weak dependence (1), average dependence (3), strong dependence (9).

(4) We add the indexes of interrelation for rows and for columns.

At this point the matrix is complete and provides us with important information regarding customer requests, as shown in Table 2.

In fact, by analyzing the table we can draw up a ranking from the most dependent to the most independent request.

We can also distinguish between the one that most influences the others and the one that influences the least.

The sum of the major line (25) indicates that the "low price" item is the most affected by the others, it is the most dependent. High values are also recorded for the "performance" item.

The sum of the major column (24), indicates instead that the "performance" item has the greatest influence on the other quantities. At a single point of distance, we find the entry concerning the "low price", which as was to be expected is very influential on the other requirements.

We now have data relating to the link between the various customer product requirements, but we do not yet have data regarding the relative importance of the various items. To obtain them starting from qualitative data it is necessary to use a second matrix, the matrix of relative importance.

The construction is similar to the previous one, but the question that now arises is the following: is the element in the row more important than the element in the column?

We use numbers like this:

$1=$ the row element and the column element have the same importance

$0=$ the row element is less important than the one in column

$2=$ the row element is more important than the one in column 
Therefore, the sum by rows classifies the absolute importance of the quantities compared in a relative way to two by two.

The last column contains the values of "normalized importance" that is the values relative to the total, normalized to the maximum value. As shown by the relative importance matrix, detailed in Table 3, the item that reaches the maximum value turns out to be "DESIGN" followed by "PERFORMANCE" and "COMFORT".

Table 2. Independence matrix.

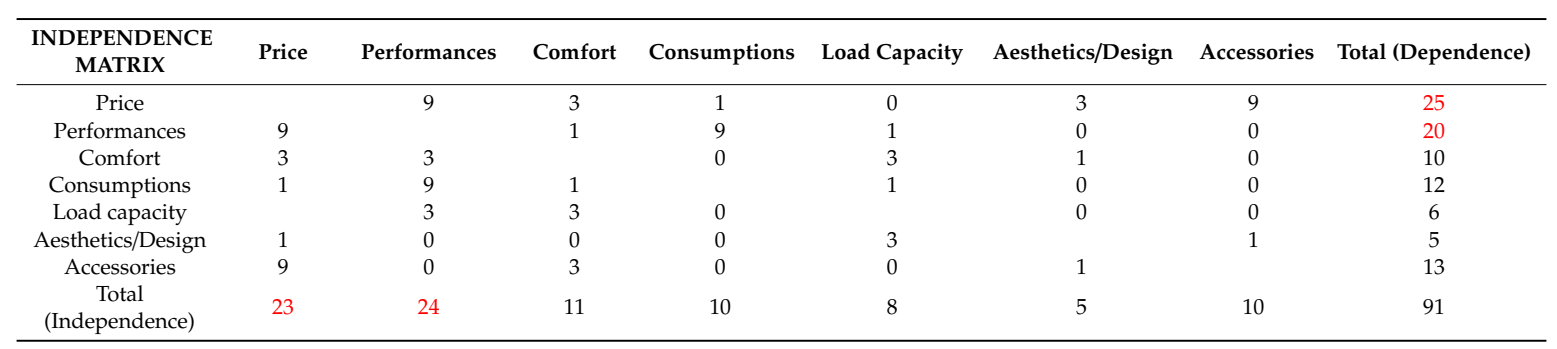

The color of the numerical values highlight the more important properties derived from the method application.

Table 3. Relative importance matrix.

\begin{tabular}{|c|c|c|c|c|c|c|c|c|c|}
\hline $\begin{array}{l}\text { IMPORTANCE } \\
\text { MATRIX }\end{array}$ & Price & Performances & Comfort & Consumptions & Load Capacity & Aesthetics/Design & Accessories & Total & $\begin{array}{l}\text { Importance } \\
\text { Normalized }\end{array}$ \\
\hline Price & 1 & 0 & 0 & 1 & 1 & 1 & 1 & 5 & 4.5 \\
\hline Performances & 2 & 1 & 1 & 1 & 2 & 1 & 1 & 9 & 8.2 \\
\hline Consumptions & 1 & 1 & 1 & 1 & 2 & 0 & 1 & 7 & 6.4 \\
\hline Load capacity & 1 & 0 & 0 & 0 & 1 & 0 & 0 & 2 & 1.8 \\
\hline Aesthetics/Design & 1 & 1 & 2 & 2 & 2 & 1 & 2 & 11 & 10.0 \\
\hline Accessories & 1 & 1 & 1 & 1 & 1 & 0 & 1 & 6 & 5.5 \\
\hline
\end{tabular}

\section{DFSS: ANALYZE}

To design an innovative hybrid executive car, it is necessary to analyze in depth the models already existing on the market. This process of study and systematic comparison between the various products on the market, takes the name of Benchmarking. Today, Benchmarking is used to indicate the methodology based on systematic comparison that allows companies that apply it to compare with the best and above all to learn from them to improve own performances.

Following the benchmarking process there is usually a review of the performance target values to be achieved and the identification of the best practices to be studied and imitated.

Once the benchmarking has been defined, the tool we are going to use later is called Top Flop Analysis, a tool that allows you to quickly compare a defined quantity of products on an equally defined number of chosen parameters. For each competitor we have considered pros and cons in terms of performances of each product. More in particular, for each parameter chosen for the comparison, the best and the worst cases, associated to the cars models presented, have been highlighted. At the end, for each car model, the sum of the best and the worst cases has been done, thus evidencing which car model can be considered the best (highest number of best cases) and which one can be considered the worst (highest number of worst cases). The cars being compared, correspond to all the hybrid models existing today, belonging to the Executive car segment. We are now going to illustrate the results of benchmarking in detail in the following sections.

\subsection{Benchmarking}

\subsubsection{Brand and Models Benchmarking}

The benchmarking analysis highlighted the most relevant brands involved in Hybrid concepts. 
Table 4, that follows, resumed the models available on the market [17-22].

Table 4. Hybrid-models benchmarking.

\begin{tabular}{|c|c|}
\hline \multicolumn{2}{|r|}{ AUDI } \\
\hline $\begin{array}{l}\text { Model: A6 } 45 \\
\text { 3.0 TDI four } \\
\text { tipt }\end{array}$ & $\begin{array}{l}\text { A very elegant long sedan that combines a } 3000 \mathrm{cc} \text { V6 Diesel engine with the Mild-Hybrid system. This system, } 48 \mathrm{~V} \text { only for } 6 \text {-cylinder } \\
\text { versions, is composed as follows: } \\
\text { A belt start generator (BSG) and a lithium ion battery allow a reduction in fuel consumption and } \mathrm{CO}_{2} \text { emissions thanks to greater energy } \\
\text { recovery as well as to the engine cut-out during journeys of less than } 60 \mathrm{~km} / \mathrm{h} \text { (inertia gear with zero emissions). } \\
\text { The permanent connection of the BSG to the combustion engine ensures comfortable starting with low vibrations. } \\
\text { What is surprising about this machine are the high values of expressible torque, which reaches } 500 \mathrm{Nm} \text {. }\end{array}$ \\
\hline \multicolumn{2}{|r|}{ BMW } \\
\hline \multicolumn{2}{|r|}{ MERCEDES-BENZ } \\
\hline Model: E 350e & 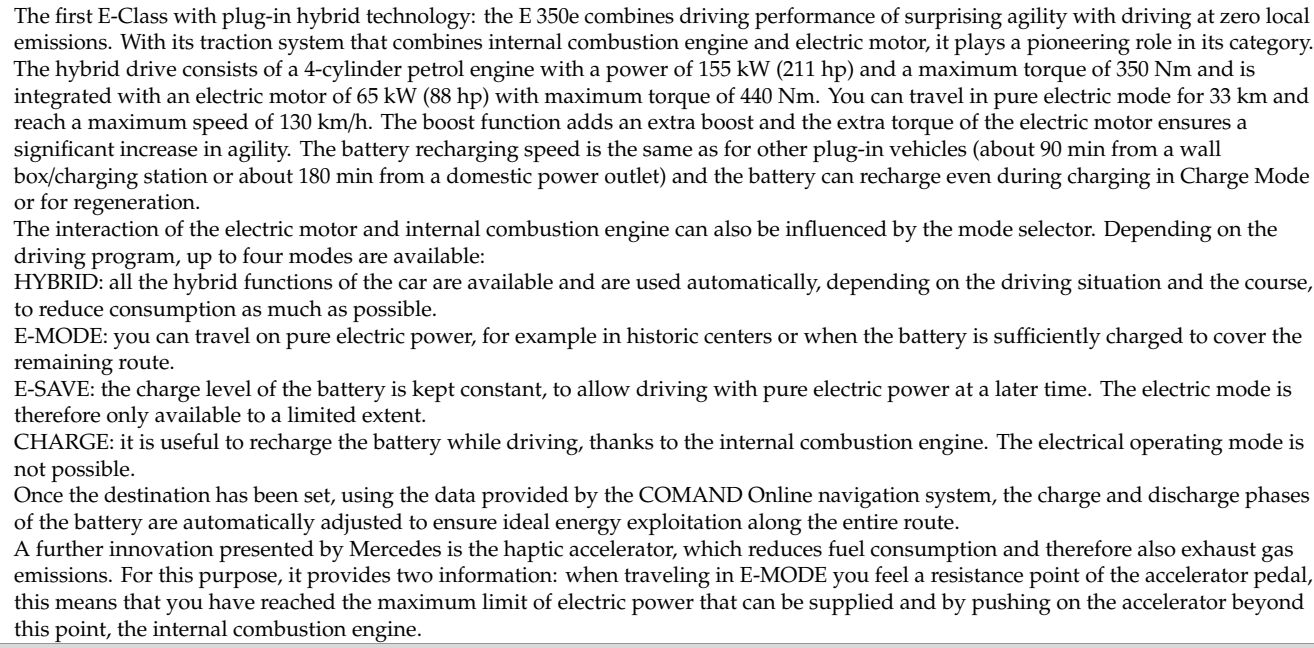 \\
\hline \multicolumn{2}{|r|}{ LEXUS } \\
\hline Model: GS 300h & $\begin{array}{l}\text { From the moment you sit behind the wheel, self-recharging batteries are ready to deliver power without the need for any prior charge. } \\
\text { Lexus Self-Charging Hybrid technology combines the power of a petrol engine with the efficiency of an electric motor. Thanks to a } \\
\text { dedicated control unit, the system is able to decide in complete autonomy when to use one motorization, the other, or both. The system } \\
\text { constantly monitors the battery charge, providing to recharge it during all the driving phases. } \\
\text { As for performance, the Lexus GS } 300 \mathrm{~h} \text { is powered by a } 2.5 \text { - } \mathrm{L}, 4 \text {-cylinder direct-injection petrol engine with } 180 \mathrm{hp} \text { at } 6000 \mathrm{rpm} \text {, and a } \\
\text { 142-hp electric unit, for a total available power of } 223 \mathrm{hp} \text {, discharged entirely on the rear wheels. Performance is clearly not a sports car, as } \\
\text { reported by the House: the maximum speed is } 190 \mathrm{~km} / \mathrm{h} \text { and acceleration from } 0 \text { to } 100 \mathrm{~km} / \mathrm{h} \text { is completed in } 9.2 \mathrm{~s} \text {. }\end{array}$ \\
\hline Model: GS 450h & $\begin{array}{l}\text { For more sporting performance just buy the older sister, equipped with a } 292 \text {-horsepower } 3.5-\mathrm{L} \text { V6 petrol engine, coupled to the hybrid } \\
\text { system that includes a } 200 \text { hp permanent-magnet synchronous electric motor for a total power of } 345 \text { horsepower. } \\
\text { These propellers move an epicycle gear train to which the generator is also connected: the system then transmits the motion to the rear } \\
\text { wheels and acts as a speed change with a continuous variation of ratio (eCvt). This more sporting set-up has a list price of around } 75,000 \\
\text { euros, the most expensive model among those analyzed. }\end{array}$ \\
\hline \multicolumn{2}{|r|}{ INFINITI } \\
\hline $\begin{array}{l}\text { Model: Q70 } \\
\text { Hybrid }\end{array}$ & $\begin{array}{l}\text { Equipped with a 3.5-L V6 petrol engine, coupled with an electric motor, it delivers } 364 \text { horsepower, which allows it to accelerate from } 0 \text { to } \\
100 \mathrm{~km} / \mathrm{h} \text { in } 5.3 \mathrm{~s} \text {, an incredible figure considering the car's weight } 1894 \mathrm{Kg} \text {. } \\
\text { But the advantages do not end there, the Q70 Hybrid is equipped with every type of comfort and cutting-edge technology such as the } \\
\text { Forest Air system that purifies the air, maintains the right level of humidity and releases a slight fragrance inside the cabin. } \\
\text { The boot is a bit limited for this version due to the presence of lithium ion batteries. } \\
\text { Another positive point to note is a very large tank }(70 \mathrm{~L}) \text {, which however will be emptied faster than the others, as the Q70 is the car with } \\
\text { the highest fuel consumption declared among its peers. }\end{array}$ \\
\hline
\end{tabular}


Table 4. Cont.

\begin{tabular}{l}
\hline \\
\hline \\
Starting from 2017, even S90 like other Volvo cars before, adopts Twin Engine technology. This technology, as we have already seen for \\
other hybrid cars, is of the Plug-In Hybrid type. \\
More than that, the Twin Engine consists of using the following system: \\
1. -PETROL ENGINE \\
2. CISG UNIT (Crank-Integrated Starter Generator) \\
3. REAR ELECTRIC MOTOR (ERAD-Electrical Rear Axel Drive) \\
4. LITHIUM ION BATTERY AND COOLING SYSTEM \\
But the S90 is still a step ahead, being equipped with the T8 Twin Engine AWD engine, available only for the 90 range, which guarantees \\
absolute performance with very low emission levels even for small hybrids. \\
The T8 Twin Engine AWD is the result of the combination of a 2-L four-cylinder petrol engine with turbocharger and volumetric \\
compressor and an electric motor, and is capable of delivering an astonishing total power-402 hp and 400 Nm-comparable to that of \\
engines with multiple cylinders. The petrol engine drives the front wheels while the rear ones receive traction from the electric motor, \\
providing instant acceleration and all-wheel drive when needed. In the "Pure" mode, with the use of the electric motor only, there are \\
zero emissions and up to 50 km of autonomy. In the "Hybrid" mode consumption is enviable and the emissions are extremely reduced.
\end{tabular}

\subsubsection{Benchmarking and Top-Flop Analysis}

Once you have gathered as much information as possible on the cars just listed, the real Top/Flop analysis begins: you decide to compare the various cars using a certain number of parameters, which give an overview of the fundamental characteristics of the car and that are relevant for a subsequent project of a similar car (Table 4).

For each parameter, the best and worst values are then identified, among those of the cars compared, coloring the green or red boxes respectively. The purpose of this analysis is to determine on each object compared what is innovative and what is not. This tool is very useful because, if you consider the best values of each car compared, you can get a set of starting values for the creation of an innovative car.

The cars were compared using the following parameters:

Length, width, height, weight, luggage capacity, number of seats, and number of doors: relating to the appearance of the car and its dimensions.

Power supply, power, displacement, maximum speed, acceleration $0-100 \mathrm{~km} / \mathrm{h}$ and maximum torque: related to the actual performance of the car.

Theoretical autonomy, electric autonomy, battery power, and time for a complete charge: characteristics relating to the electric motorization.

Price

For each of these parameters, the "best value" was sought, that is, what is deemed to be preferable by the customer. Therefore, depending on the case, in green or in red we will have the highest or the lowest value.

For example, regarding the dimensions (LENGTH, HEIGHT, WIDTH), we chose to consider smaller values as "better". As regards the capacity of the tank and the boot, the highest value obtained is considered to be the best.

Once the table is drawn up, we insert below it an additional table (present in the image), where we report for each car compared, the number of best values (TOP) and the number of worst values (FLOP) obtained (Table 5). Making the difference between the number of TOP values and the number of FLOP values we get DELTA. The $\Delta$ represents the innovativeness of the car as it is obtained as a gap between the values identified as best and those identified as worst. The sedans that turn out to be the most innovative are those with $\Delta$ greater. Creating a more innovative car will mean overcoming or equaling the found, to do so it is sufficient that the $\Delta$ of the designed car is greater than the highest delta obtained among the cars in the table.

Once the maximum is known, we take the "best values" or TOP values, relative to each parameter individually, and insert them in the column next to the table, which takes the name of innovation column and for reasons of space has not been inserted previously. 
Each value will be accompanied by a <or $>$ in the case in which they must be increased or handicapped to be improved. The maximum value of $\Delta$ is 2 . This means that the new hybrid car will have to improve at least 3 parameters compared to those in the innovation column.

Table 5. Benchmarking and Top Flop analysis table.

\begin{tabular}{|c|c|c|c|c|c|c|c|c|}
\hline Brand & AUDI & BMW & KIA & MERCEDE & \multicolumn{2}{|c|}{ LEXUS } & INFINITI & VOLVO \\
\hline Model & A6 & 5 Series & Optima & E Class & GS 300h & GS 450h & Q 70 & S90 \\
\hline TOP FLOP ANALYSIS & & & & & & & & \\
\hline Lenght [mm] & 4940 & 4940 & 4860 & 4920 & 4880 & 4880 & 4980 & 4960 \\
\hline Width [mm] & 1890 & 1870 & 1860 & 1850 & 1840 & 1840 & 1850 & 1880 \\
\hline Height [mm] & 1460 & 1480 & 1470 & 1470 & 1460 & 1460 & 1490 & 1440 \\
\hline Weight $[\mathrm{kg}]$ & 1900 & 1845 & 1780 & 1925 & 1735 & 1825 & 1894 & 2019 \\
\hline Trunk capacity $\left[\mathrm{dm}^{3}\right]$ & 530 & 410 & 307 & 540 & 450 & 450 & 350 & 500 \\
\hline Supply & HYB. & HYB. & HYB. & HYBRID & HYB & HYB. & HYB. & HYB. \\
\hline Displ. $\left[\mathrm{cm}^{3}\right]$ & 2967 & 1998 & 1999 & 1991 & 2494 & 3456 & 3498 & 1969 \\
\hline Power $[\mathrm{Kw}]$ & $210(286)$ & $185(252)$ & $151(205)$ & $210(286)$ & $164(223)$ & $254(345)$ & $268(364)$ & $296(402)$ \\
\hline Max Sp. $[\mathrm{km} / \mathrm{h}]$ & 250 & 235 & 192 & 250 & 190 & 250 & 250 & 250 \\
\hline $\begin{array}{l}\text { Acceleration } \\
0-100 \mathrm{~km} / \mathrm{h}[\mathrm{s}]\end{array}$ & 6.3 & 6.2 & 9.4 & 6.2 & 9.2 & 5.9 & 5.3 & 5.1 \\
\hline Max Tor. $[\mathrm{Nm}]$ & 500 & 290 & 189 & 350 & 221 & 352 & 350 & 400 \\
\hline Price [Euro] & 64.000 & 65.000 & 44.000 & 68.000 & 58.000 & 75.000 & 65.000 & 73.000 \\
\hline Tank [liter] & 63 & 46 & 55 & 66 & 66 & 66 & 70 & 50 \\
\hline Av. Cons. [L/100 km] & 5.67 & 1.9 & 1.7 & 2.6 & 4.9 & 6.3 & 6.7 & 2.1 \\
\hline $\mathrm{CO}_{2} \mathrm{Em} .[\mathrm{g} / \mathrm{km}]$ & 146 & 44 & 37 & 57 & 113 & 145 & 145 & 46 \\
\hline Th. Aut $[\mathrm{km}]$ & & 2300 & 3400 & 2380 & 1400 & 1100 & 1127 & 2500 \\
\hline El. Aut $[\mathrm{km}]$ & 3 & 46 & 54 & 33 & & & & 40 \\
\hline Battery [kWh] & 1.3 & 9.2 & 9.8 & 6.2 & & & & 9.2 \\
\hline Charging times [h] & & 4 & 6 & 3 & & & & 4 \\
\hline Number of TOP & 2 & 0 & 7 & 2 & 2 & 2 & 3 & 2 \\
\hline Number of FLOP & 4 & 1 & 5 & 0 & 1 & 2 & 3 & 2 \\
\hline Delta $\Delta$ & -2 & -1 & 2 & 2 & 1 & 0 & 0 & 0 \\
\hline
\end{tabular}

The cells colored in red and in green evidenced the best and worst cases.

After completed, the TOP-FLOP analysis is possible to collect all the targets that performances of the new car must reach, by collecting the data into an Innovation List Targets Table (Table 6).

Table 6. Innovation list targets table.

\begin{tabular}{|c|c|}
\hline Innovation Column & Ideal Car \\
\hline Lenght $[\mathrm{mm}]$ & $<4860$ \\
\hline Width [mm] & $<1840$ \\
\hline Height [mm] & $<1440$ \\
\hline Weight $[\mathrm{kg}]$ & $<1735$ \\
\hline Trunk capacity $\left[\mathrm{dm}^{3}\right]$ & $>540$ \\
\hline Supply & HYBRID \\
\hline Displacement $\left[\mathrm{cm}^{3}\right]$ & $>3500$ \\
\hline Power [Kw (hp)] & $>296(402)$ \\
\hline Max Speed $[\mathrm{km} / \mathrm{h}]$ & $>=250$ \\
\hline Acceleration $0-100 \mathrm{~km} / \mathrm{h}[\mathrm{s}]$ & $<5,1$ \\
\hline Max Torque $[\mathrm{Nm}]$ & $>500$ \\
\hline Price [Euro] & $<44.000$ \\
\hline Tank [liter $]$ & $>70$ \\
\hline Average Consumptions [L/100 km] & $<1.7$ \\
\hline $\mathrm{CO}_{2}$ Emissions $[\mathrm{g} / \mathrm{km})$ & $<37$ \\
\hline theoretical Autonomy $[\mathrm{km}]$ & $>3400$ \\
\hline Electric Autonomy [km] & $>54$ \\
\hline Battery $[\mathrm{kWh}]$ & $>9.8$ \\
\hline Charging times $[\mathrm{h}]$ & $<3$ \\
\hline
\end{tabular}

Moreover, in order to understand which of these parameters is most advantageous to improve, we use an additional tool, the what-like matrix. 
The customer's requirements (what) are compared to the designer's answers (how) (Table 7).

Table 7. What/how matrix.

\begin{tabular}{|c|c|c|c|c|c|c|c|c|c|c|c|c|c|c|c|c|c|c|c|c|}
\hline 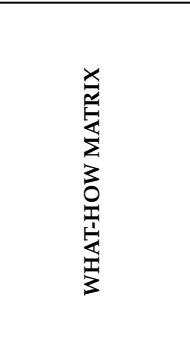 & 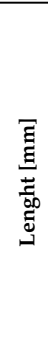 & 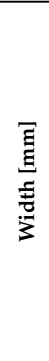 & 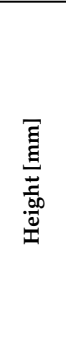 & 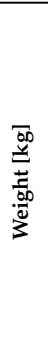 & 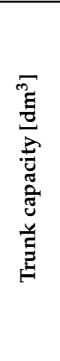 & $\begin{array}{l}\vec{\lambda} \\
\frac{2}{2} \\
\frac{\vec{n}}{n}\end{array}$ & 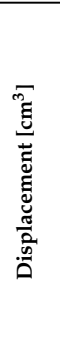 & 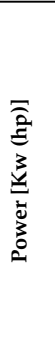 & 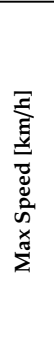 & 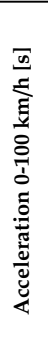 & 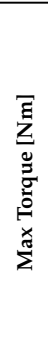 & 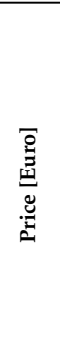 & 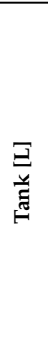 & 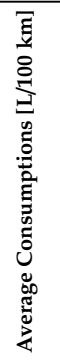 & 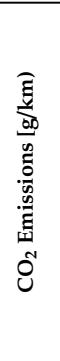 & 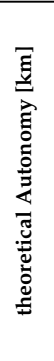 & 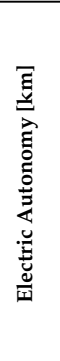 & 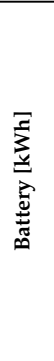 & 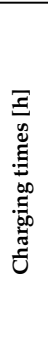 & ฮొ \\
\hline Price & & & & 1 & & & 9 & 9 & & 9 & & & & 1 & & & & & & \\
\hline Perforn & & & & 3 & & 3 & 3 & 9 & 9 & 9 & 9 & 3 & & 9 & 3 & 1 & 3 & 1 & 1 & \\
\hline & 9 & 9 & 9 & 1 & 3 & & & & & & & 3 & & & & & & & & \\
\hline & & & & 3 & & 3 & 9 & 3 & 1 & 1 & 1 & & & 9 & 9 & & 9 & 3 & 1 & \\
\hline heti & 1 & 1 & 1 & 1 & 3 & & & & & & & 3 & & & & & & & & \\
\hline Total & 10 & 10 & 10 & 9 & 6 & 6 & 21 & 21 & 13 & 19 & 19 & 18 & ( & 19 & 12 & 11 & 13 & 5 & 3 & \\
\hline
\end{tabular}

A matrix is then prepared with in line the requirements to be satisfied and in column the means that make the realization of that requirement possible.

In line we then insert the customer's needs and in the column the parameters used to perform the Top Flop Analysis, modifying which, it will be possible to meet the customer's requests.

The client's requirements listed above will not all be entered in the table, but will be filtered so as to insert only the items that have obtained the highest values in the interrelation matrices.

Also, in this case numerical evaluations on the type of relation will be used: nothing (empty box, equivalent to 0 ), weak (1), medium (3), strong (9).

We then found the sums by rows and by columns:

The maximum value of the line sum indicates which requirement is the most influenced by the parameters in the column.

The maximum value of the sum of the column indicates which parameter is the most important in order to reach the customer's requests.

Now let's highlight the parameters that have obtained the highest values of the column sums:

- DISPLACEMENT, POWER, ACCELERATION, and MAXIMUM TORQUE: These four parameters are redundant, they are all related to the performance and therefore to the car's engine, so it will be sufficient to improve one only of them to obtain an increase of the others.

- PRICE

- AVERAGE CONSUMPTION

Then going on to analyze the line sums, we note that the larger values are obtained from the entries:

- $\quad$ LOW PRICE

- PERFORMANCE

- LOW CONSUMPTION

This means that these three requirements are the most influenced by the parameters studied and therefore also easier to obtain

Based on the information collected, we aim to design an innovative hybrid sedan, improving the following 3 parameters:

- $\quad$ Power (weight-power ratio)

- Price

- Average consumption

A more detailed study of the possible viable solutions is now necessary in order to improve the parameters. 
Power

The choice of power as a parameter to be increased was dictated by its strong influence on the performance of the machine both in terms of acceleration, maximum speed, torque, etc.

What is going to affect power is clearly the choice of the propulsion group. The choice of a high-performance heat engine can be ideal for achieving high torque and acceleration values, which give the car a sportier character.

At the same time, a very heavy engine would worsen the car's performance in terms of consumption. The right compromise must therefore be sought that allows good results to be achieved in terms of performance, without a substantial increase in the price and consumption of the car.

This leads us to an important first choice, which type of hybrid should be used?

Depending on the degree of hybridization, three different types of hybrid can be defined:

a. Full hybrid or full hybridization cars: this type of hybrid cars adopts the classic heat engine, petrol or diesel, one or more electric motors of rather high power, a 400 Volt electric system and batteries of such a capacity as to allow the car to travel a few kilometres in purely electric mode i.e., zero emissions. The two motors are normally coupled via a CVT continuously variable transmission or via a converter or double-clutch automatic transmission. The symbiosis of the two engines, the thermal and the electric one, is then guaranteed by the electronics that manage their operation, allowing both engines to obtain and guarantee the best total efficiency. Precisely for this reason full hybrid cars are able to move forward using only the heat engine or just the electric motor or the combination of both (Figure 2).

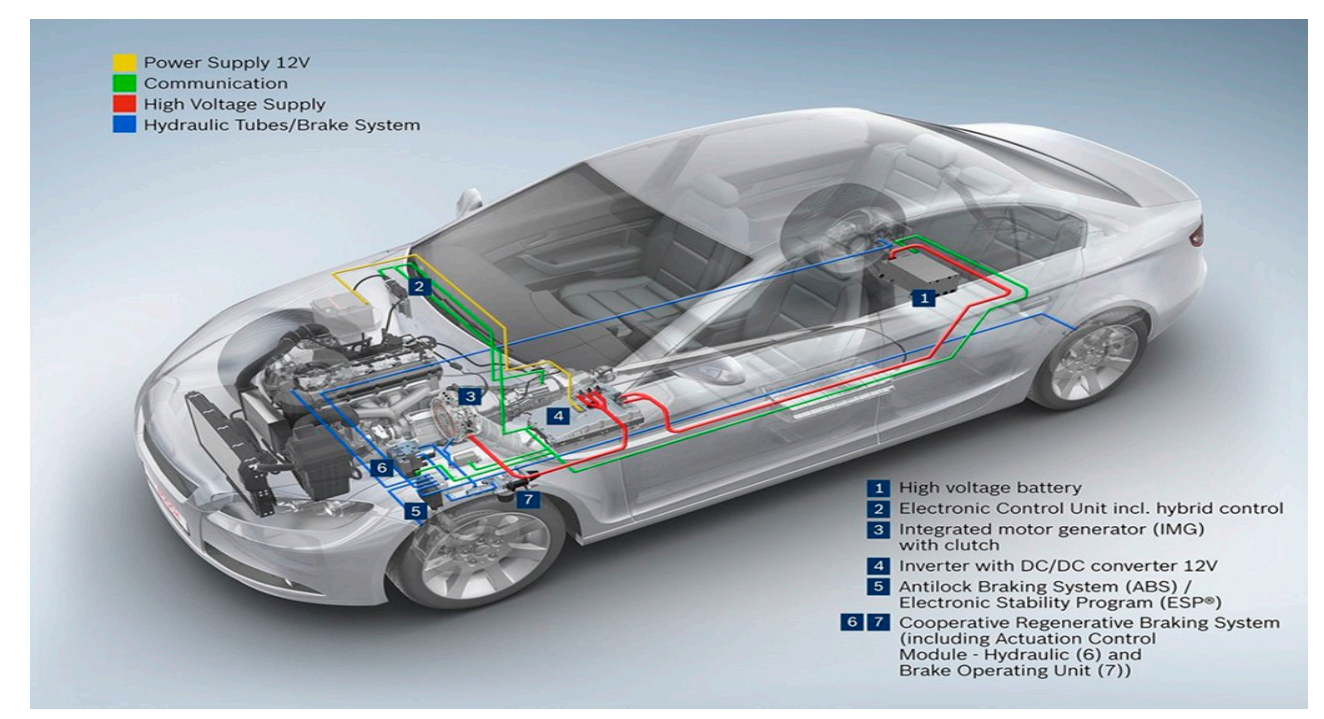

Figure 2. Full hybrid car architecture [23].

The same heat engine, in case it was needed, can be declined in addition to traction even when recharging the same battery pack. Furthermore, the heat engine is always switched off when not necessary, such as during stops, or the car can be left sailing with both engines disconnected. Finally, in the deceleration and braking phases, the electric motor is used as a current generator to implement regenerative braking so as to recharge the battery pack by exploiting the kinetic energy that would otherwise be lost in heat in the brakes.

b. Mild hybrid or light hybridization vehicles: this type of hybrid cars adopts the classic heat engine, petrol or diesel, an electric motor/generator of modest or reduced power (replacing the classic alternator), a 48 Volt electrical system and lithium-ion batteries of smaller capacity, separated from the rest of the electrical system, which allows the car to travel several hundred meters with only electric traction (Figure 3). The real novelty of the mild hybrid system is the 48 Volt electrical system which, replacing the high voltage system (400 Volt) of the full hybrid systems, goes alongside the classic 12 
Volt electrical system. This design choice has allowed on the one hand to adopt 48 Volt motors and battery packs so up to 4 times more powerful than the 12 Volt ones, on the other hand to limit the voltages so as to reduce the cable size by as much as $75 \%$ so as to contain costs, dimensions and weight of the wiring. As with full hybrids, if more power is required, the electric motor/generator gives its additional boost to the heat engine. In deceleration or braking, on the other hand, the engine/generator acts as a brake to charge the battery with energy that would otherwise be lost.

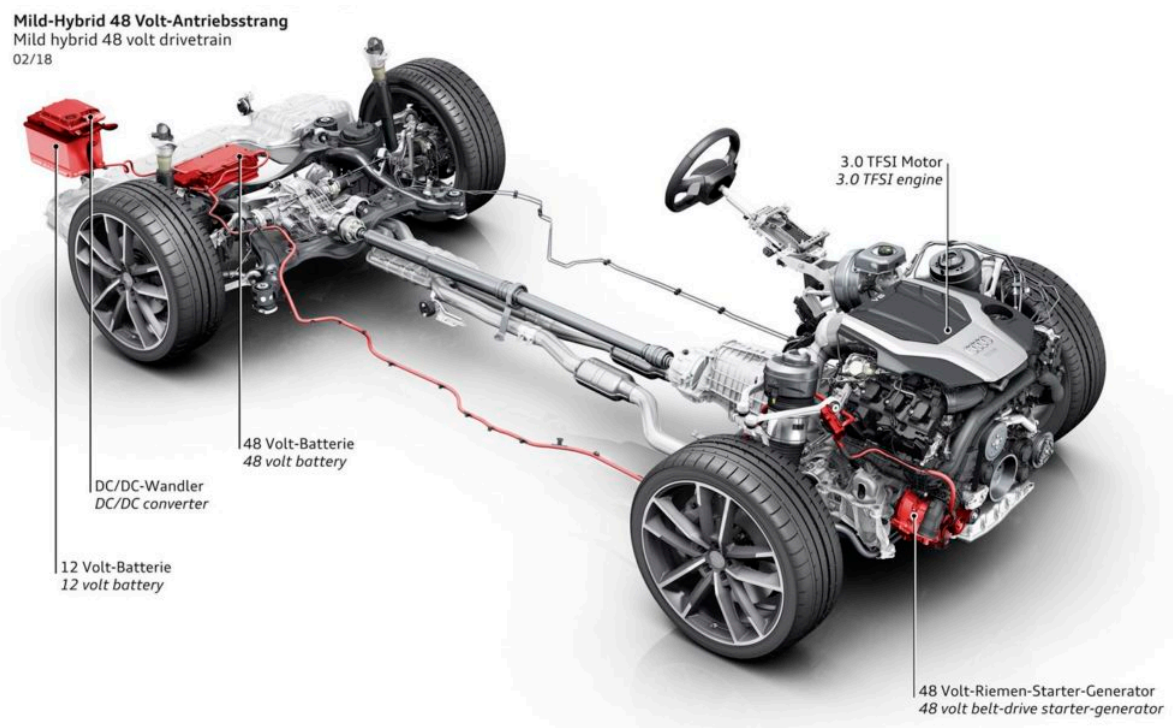

Figure 3. Mild hybrid car architecture [24].

c. Plug-in hybrid cars: This type of hybrid cars fully reflects those just described of the full hybrid type, with the only difference that they add a power socket for recharging the battery pack via the mains (home or post) and a battery pack of greater capacity allowing in this so the hybrid car can travel a greater distance in purely electric mode, that is to say with zero emissions. For the rest they are identical to full hybrid cars and therefore share their strengths and weaknesses in addition to the construction scheme (Figure 4).

Case Study Choice. After the above mentioned analysis, project choice falls on a full Hybrid petrol engine, which does not require an external recharge and is therefore more suitable for long journeys without the need for frequent recharges. Furthermore, having to design an E-segment sedan, which will be used more frequently in suburban areas, the high electrical autonomy of Plug-In hybrids is not necessary. This choice makes it possible to minimize the size and weight of the electric motor by optimizing the efficiency of the machine in terms of consumption and performance. As for the type of engine, it was decided to use the same engine as the Lexus $450 \mathrm{~h}$, which is capable of delivering 345 horsepower. Therefore, the actual power of the car will not be the highest among those analyzed, because the use of an even more powerful engine would lead to a further increase in costs and consumption. For this reason, the parameter that we propose to improve will be the weight-power ratio.

\section{Price}

The total price of the motorcycle will be determined both by the quality and quantity of the components used, which affect variable costs, and by project and management costs, or fixed costs, compared to the number of volumes, all multiplied by a coefficient $k$ (typically values less than 3 are not used).

$$
\text { Unit Price }=[\text { Variable Costs }+ \text { Fixed Costs } \times \text { Sales Volumes }] \times k
$$


In particular, under the heading of fixed costs all expenses related to the phases of research and development must be included, therefore costs of prototyping, analysis of the materials and work of the engineers, then the expenditure on production plants and the cost of services, electrical, logistics and marketing. Among all the items that are part of the costs, we are able to intervene exclusively on the expenses related to the design and construction of the car itself. The elements that can determine a price increase/decrease are mainly the following:

- $\quad$ Presence of accessories

- Engine

- $\quad$ Use of expensive materials

It will therefore be necessary to design a car that has the necessary accessories for a saloon of this type, but without an excess of technology that would lead to a rise in prices. As already mentioned, the right compromise between performance and cost of the propulsion system will be sought. Finally, it will be necessary to study solutions that allow to achieve optimal results with the use of low-cost materials.

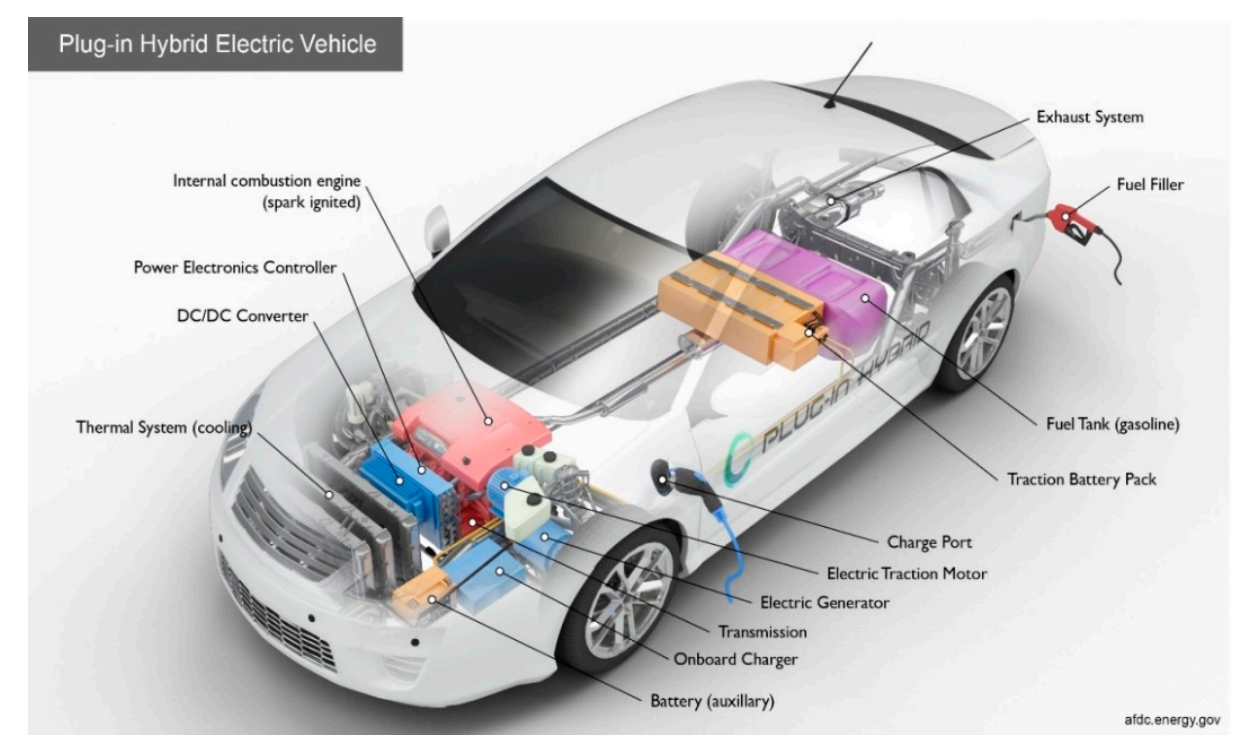

Figure 4. Plug-in hybrid car architecture [25].

\section{Average Consumptions}

The presence of the hybrid engine generally allows to save more than $25 \%$ of fuel compared to a petrol engine. To make our car even cheaper, it will be essential that the electric motor and the petrol engine are managed as efficiently as possible by the electronics, so as to exclusively use the electric motor whenever possible and save the battery instead when on suburban roads.

An innovative solution already used by Mercedes could be the haptic accelerator, which by providing a resistance on the accelerator pedal, indicates that the maximum limit of deliverable electric power has been reached and pushing the accelerator beyond this point the engine would start to operate internal combustion.

This would allow a more informed guide by the user, followed by a not inconsiderable reduction in consumption.

Even the size of the rims is not negligible in a maximum efficiency optic, the use of smaller rims leads to lower consumption but less rigidity and road holding.

The weight of the car will be even more important in this respect. Reducing it would have benefits in all areas that we set out to improve. Therefore, a further study will be required to reduce the weight of the car as much as possible. 


\section{DFSS: DESIGN}

After collecting some information necessary for the design of the car, we move on to the design of the chassis, choosing the type that best suits the type of car.

In general, the frame has the dual purpose of ensuring the connection of the various groups making up the vehicle and carrying the body and the load. The construction of a frame of this type does not require the maximum possible machining precision, however the dimensions that define the attachment points of the various organs must be scrupulously respected. During vehicle operation, the frame is subjected to various and complex mechanical stresses, which cannot always be accurately assessed during the design phase. In principle, the frame must meet the following requirements:

(1) Be built with material having high fatigue resistance.

(2) Having a shape that offers good resistance to deformation.

(3) Have a relatively low weight so as to keep the weight-power ratio low.

The types of frames used for road machinery are the following:

FRAMES WITH LONGWAYS AND CROSSPIECES (ladder frame): It consists of a pair of parallel spars connected together by simple crossbars. The side members and cross members are fitted with appropriate brackets, brackets and supports for attaching the suspensions and for fixing the various groups making up the vehicle itself. Depending on the type and shape of the body and the loading and use conditions, the side members take different forms (Figures 5 and 6).

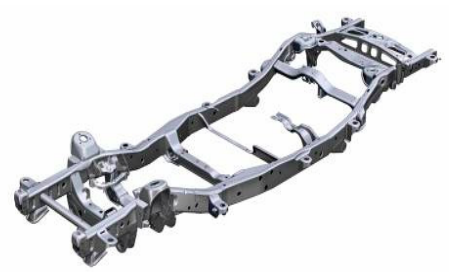

Figure 5. Ladder frame, first configuration.

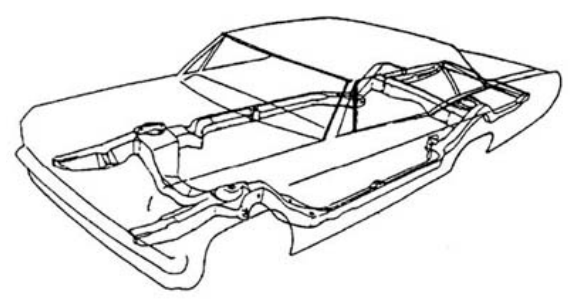

Figure 6. Ladder frame, second configuration

Advantages: This type of frame is simple and inexpensive to design and build; presents a great versatility as different bodies can be mounted on the same frame. It has good flexural strength and stiffness and discreet torsional stiffness when equipped with suitable reinforcements. It is used in vehicles suitable for heavy transport, with high vertical loads supported by sturdy side members, or in all those that do not require excellent driving precision in their use (off-road or SUV).

Disadvantages: As long as the structure remains two-dimensional, that is without calculating the additional strength and stiffness of the body, even if properly reinforced it has a torsional stiffness much lower than that of all the other types of known frames.

With equal rigidity, the weight is $10-15 \%$ higher than the monocoque.

BACK SPROCKET (chassis backbone): This type of frame consists of a central tunnel with a rectangular section or a tube frame. The so-called "backbone" connects the front axle with the rear axle and provides all the mechanical strength of the car by itself. The substructures supporting the suspensions, masses and engine are integral to the tunnel. The Backbone Chassis is very suitable for cars with two and four seats, where the size of the tunnel can be used as an armrest between the seats. 
The greater the height of the tunnel the greater the torsional stiffness (in any case greater than the ladder frame).

Advantages: The "chassis backbone" or tunnel frame is strong enough for small sports cars. It has a torsional stiffness that is not very high but still superior to that of the "ladder frame". Simple to build by hand and economically for small production volumes.

Disadvantages: Does not protect against side impacts. It requires additional reinforcements in the bodywork and is inconvenient for high production volumes (Figure 7).

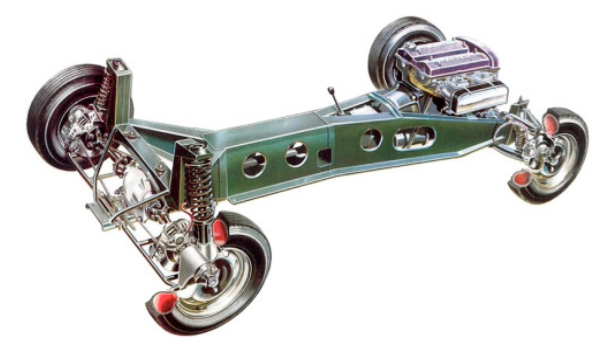

Figure 7. Chassis backbone.

TUBULAR FRAME (space frame): In some sports cars of very limited production or competition, frames with a high stiffness/weight ratio are obtained by joining tubes. If the frame has been designed correctly, the forces coming from the suspension attachments are discharged on several pipes, lowering the amount of mechanical stress. The tubes can have different sections depending on the direction of the stress: a round section is used to withstand possible impacts having an unknown direction, instead elliptical, square or rectangular sections are used when the stress is known or slightly variable in the direction to favor resistance or the stiffness of the pipe in one direction over another.

These cars have a remarkable lightness also because it is possible to use bodies built with low-density metal alloys (aluminum-based) or with very light complex polymeric materials that do not have a load-bearing function in most cases.

A tubular frame, in its simplest configuration, consists of a welded tube truss and does not alone perform the task of withstanding all stresses; even the engine and some bodywork wallpaper can have a supporting function. A tubular frame "space frame" is by definition a reticular structure formed by tie rods and struts connected together so as to form triangular geometries. This frame, in its currently more complex configuration, consists of various types of elements of different materials and processing technologies, which can be theoretically independently designed. Whether it is a simple tubular frame or space frame, the structure is designed to have a very high stiffness.

Advantages: The tubular frame is very resistant compared to the frame with longitudinal and cross members or to the monocoque frame (see next paragraph) for the same weight; it also has high stiffness/weight ratios, exceeded only by carbon fiber frames.

Disadvantages: Complex and expensive, it requires long manufacturing times. Not robotically feasible. Raise the lower threshold of the doors, making living space difficult (Figures 8 and 9).

LOADING BODY (unibody): The bearing body in pressed steel sheet has for decades been the most adopted solution by all the automotive industries for standard production cars, so much so that it is used by $95 \%$ of the vehicles currently in production. The main reason lies in the general qualities, in the cheapness and in the great adaptability to the automated production, coupled to the good level of the obtained performances [26-30].

The body is defined as a carrier when it has a mechanical resistance such as to support its own weight and that of the various groups making up the vehicle. In this way, a single structure is created to which the engine and the other vehicle groups are applied directly. What we try to achieve in any case is a high torsional rigidity, to prevent the deformation of the monocoque affecting the road holding. In fact, if the body is subjected to forces that subject it to torsion, the vibrations have a similar frequency 
or at the limit coinciding with that of damping the suspensions, for this reason there is a negative effect for stability.

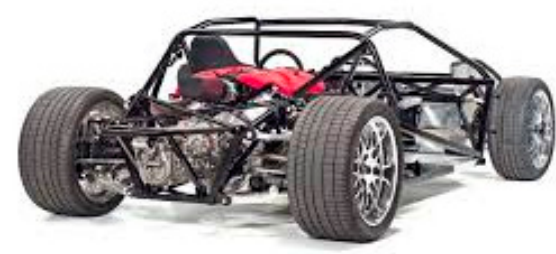

Figure 8. The space frame, first configuration.

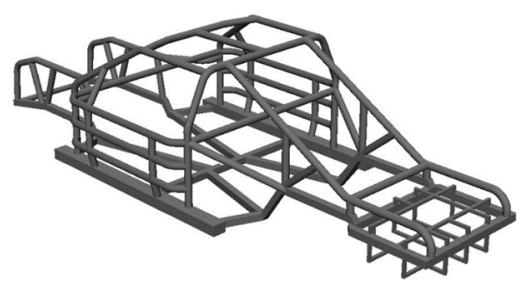

Figure 9. The space frame, second configuration.

Advantages: The monocoque frame (steel unibody) generally has a very economical base material (low carbon steel sheet: $0.8 \%$ by weight). A great economy for high productions, with high investments only in the initial phase of production (high cost of the molds). Full adaptability to mass production. Good behavior to crash. Excellent use of space, with high habitability and accessibility.

Disadvantages: Intrinsic heaviness, with the same torsional stiffness, compared to the tubular frame, due to the quantity of material used. High costs for vehicles with low to medium production volumes (Figure 10).

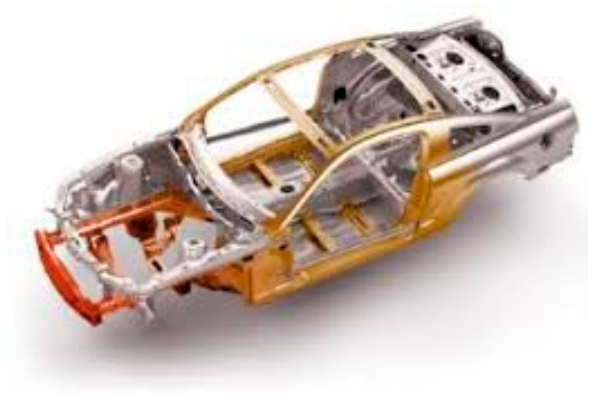

Figure 10. Unibody.

CARBON FIBER SHELL: Carbon fiber is the most sophisticated material available today; it is used for high-class or competition sports cars. The carbon fiber bodies have the highest performance ever, at least as regards the stiffness-to-weight and strength-to-weight ratio; but their adoption on standard cars presents some problems both from the economic point of view determined by the cost of the material, and from the productive one determined by the impossibility of automating the production process itself causing in fact a great slowness of processing; moreover the recyclability of the material in the event of a collision is also difficult.

Advantages: The carbon fiber body is the lightest and most rigid structure available today for a car.

Disadvantages: The basic raw material is very expensive and the manufacturing process is very slow, therefore, it is not suitable for mass production (Figure 11). 

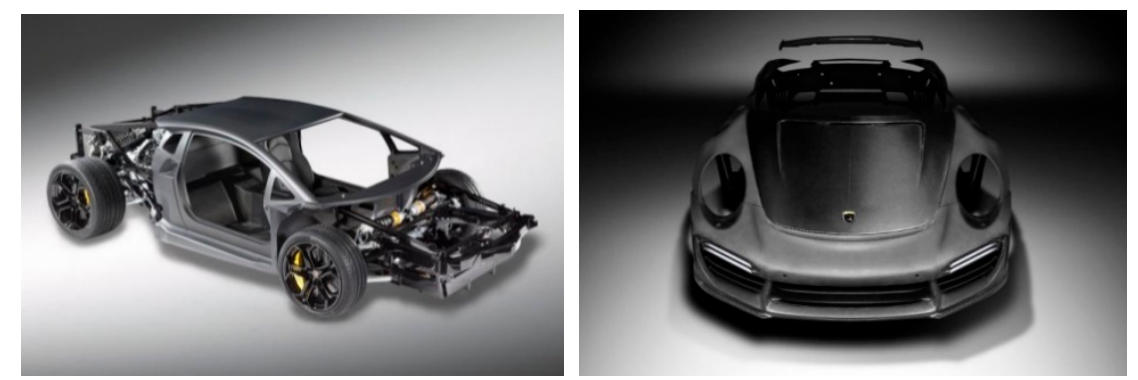

Figure 11. Carbon fiber shell.

\subsection{Choice of the Frame Type}

Once all the possibilities have been analyzed, a tubular type frame is chosen. This choice is driven by the need to design a car that has a high power/weight ratio; the tubular frame in fact, for the same weight, is more resistant than all other types of frame. These features allow us to create a lighter frame, without weakening the structure and maintaining adequate stiffness for the car's required performance.

\subsection{Choice of the Material}

The choice of the material of which the frame will be made, will be influenced by the needs and objectives that we have set before:

- Decrease in the price of the car

- Decrease in consumption

- Increased power/weight ratio

It is clear that a reduction in the weight of the car positively influences 2 of the 3 objectives we set ourselves.

In fact, in the normal urban/highway cycle only $25 \%$ of the engine power is needed to overcome the air resistance, instead $70-75 \%$ is related to the weight of the car. The inertia forces that manifest themselves in the acceleration or braking phase, the resistant components in uphill routes, the rolling friction forces and the friction in the transmission mechanisms depend on the weight. The reduction in the weight of the car would therefore allow a simultaneous improvement in performance and a reduction in consumption.

We must not forget that even the price of the car is among the objectives to be minimized, so it will be necessary to choose a relatively cheap material. Once the required properties of the material that will make up the machine frame have been identified, the vehicle is equipped with an aluminum frame.

The choice is mainly guided by the lightness properties of aluminum, which has a density equal to one third of that of steel, as shown in Table 8. This feature makes it possible to build lighter structures, although the weight of the structure will not respect the proportion between the densities. This will be due to the use of larger and therefore heavier diameter pipes, to guarantee greater rigidity to the aluminum frames. Nevertheless, weight reduction will be significant, bringing the desired benefits. Furthermore, aluminum does not suffer from the problem of rust or even the typical weakening of the areas affected by welding. Or rather, the welding weakens the frame anyway, but it is possible to return practically to the original resistance values with appropriate treatments, which, unfortunately, cannot be carried out for steel.

Table 8. Materials' density comparison.

\begin{tabular}{cc}
\hline \multicolumn{2}{c}{ DENSITY } \\
\hline Material & $\mathrm{d} \mathrm{kg} / \mathrm{dm}^{3}$ \\
Aluminum & 2.70 \\
Titanium & 4.50 \\
Steel & 7.80 \\
\hline
\end{tabular}


These properties, combined at a cost that is still more limited than more valuable materials, such as carbon fiber or titanium, make aluminum the best material for the tubular frame that we're going to design.

Clearly the material that will make up the frame will not be pure aluminum, but its alloy, this solution will allow us to have better mechanical properties and to choose from a wide range of alloys.

Now let us list the main aluminum alloys and their properties in Table 9.

Table 9. The main aluminum alloys' properties.

\begin{tabular}{cl}
\hline \multicolumn{1}{c}{ ALLUMINIUM ALLOYS' CHARACTERISTICS } \\
\hline Series 1000 & $\begin{array}{l}\text { This composition is characterized by excellent corrosion resistance, high thermal and electrical } \\
\text { conductivity, low mechanical properties and excellent workability. It is possible to have hardenings for } \\
\text { cold working. }\end{array}$ \\
\hline Series 2000 & $\begin{array}{l}\text { The presence of copper allows for an increase in properties following heat treatment, which can be further } \\
\text { improved with artificial aging. These alloys are often plated with high purity } 6000 \text { and } 7000 \text { alloys which } \\
\text { give physical and electrolytic protection to the heart and increase the resistance to corrosion }\end{array}$ \\
\hline Series $\mathbf{3 0 0 0}$ & $\begin{array}{l}\text { Manganese is the most common alloy; they are thermally untreatable alloys and possess a high resistance } \\
\text { to corrosion and high formability. }\end{array}$ \\
\hline Series 5000 & Magnesium gives good weld ability and excellent corrosion resistance. \\
\hline Series $\mathbf{6 0 0 0}$ & $\begin{array}{l}\text { The simultaneous presence of silicon and magnesium determines the possibility of heat treatment; they } \\
\text { have good formability, high resistance to corrosion with high mechanical properties. }\end{array}$ \\
\hline Series 7000 & It has good mechanical properties but a high cost. \\
\hline
\end{tabular}

Looking for a compromise between alloys with good mechanical properties and low price, we discard the alloys of the 6000 and 7000 series, which despite having excellent mechanical properties, have too high a cost that would meet our goal of containing the price.

We then choose a 2000 series alloy, which will be subjected to heat treatment, in order to obtain an improvement in mechanical performance.

\subsection{Design of the Frame}

After choosing the material, all that remains is to start with the actual design of the frame.

For a correct design it is necessary to know first the height, length, and width of the car. With these data it is possible to make a first sketch of the car's floor, equipped exclusively with side members, flame arrester, luggage compartment, and special spaces for the wheels [31-33].

\subsubsection{Static Verification}

Every time a sketch is completed, a static analysis of the structure created must be carried out, to verify that it responds adequately to the loads and that there are no points of weakness or errors in the design.

All this is accomplished through a simulation software, which will allow to have information about:

- $\quad$ Stress

- Deformation

- Moving

The following loads are applied to the structure:

- Motor weight

- Weight of frame + body + windows (estimated)

- Weight of the 2 front passengers (75 kg each)

- Weight of the 3 passengers behind (75 $\mathrm{kg}$ each)

- Full tank weight

- Full boot weight 
Once all the calculations and estimates have been made, it is possible to apply the individual loads to the relative components of the frame on which they rest.

Once this is done, the constraints are imposed on the structure, consistent with the wheel-frame coupling.

The study is then carried out which will highlight the tensions, deformations, and displacements to which the structure is subjected.

Frame without Plates

The initial sketch of the frame includes the insertion of the platform, the firewall, the tubes that will make up the bonnet and the rear part relative to the trunk. The first sketch is certainly the most difficult to make as it is necessary to be able to match all the frame sizes, so as not to have any surprises later when going to perform the verification in Layout, inserting seats, mannequins, and wheels (Figure 12).

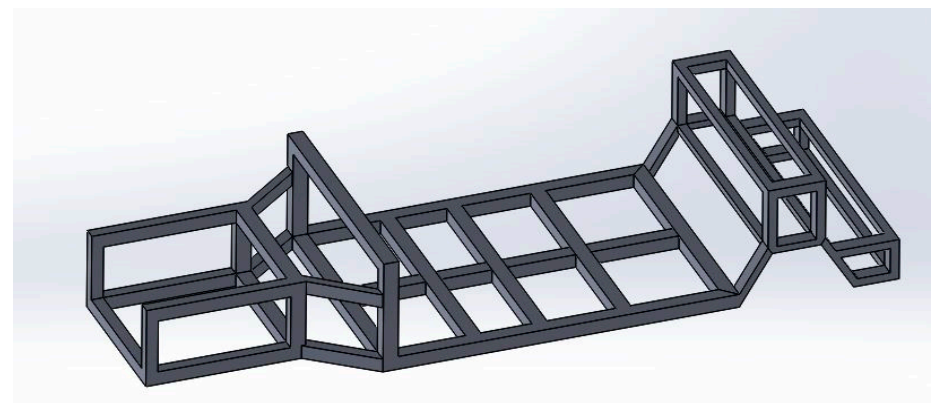

Figure 12. Frame without plates designed.

As you can see, in fact, the three crossbars that extend over the entire length of the platform are deliberately at different distances from each other, this because when we would later go to insert the seats, it will be necessary to have more space available underneath passengers' feet. This solution allows us to install the seats lower down, gaining space in height.

We will now proceed to the analysis of the structure following the parameters previously indicated (Figures 13-15) [32,33].

All of the analyses are displayed in the "deformed state" function of the program that helps the understanding of the user by highlighting the structure deformation.

From the first analysis we can consider ourselves very satisfied, in all three fields in fact, the frame reacts well to the loads to which it is subjected. The maximum load is in fact $13.8 \mathrm{MPa}$, an acceptable value considering that the chosen material has a yield strength of $290 \mathrm{MPa}$.

As expected, the most stressed area appears to be the platform that has the maximum displacements. Even in this case, however, the result is more than acceptable.

In addition to verifying the most stressed areas, it is equally important to check which areas are less subject to loads and deformations so as to be able to perform a possible under sizing that allows to reduce the weights and the overall dimensions. As we can see, in fact, the upper beams that make up the trunk are practically free of loads, so you choose to eliminate the rear beam, so as to have easier access to the trunk and a lower weight of the structure.

Although the structure has achieved reasonable results, it is clear that further reinforcement and stiffening is required in specific areas.

Therefore, some sheets are added to connect the various beams, so as to have a more uniform distribution of the loads and a greater rigidity of the structure. 


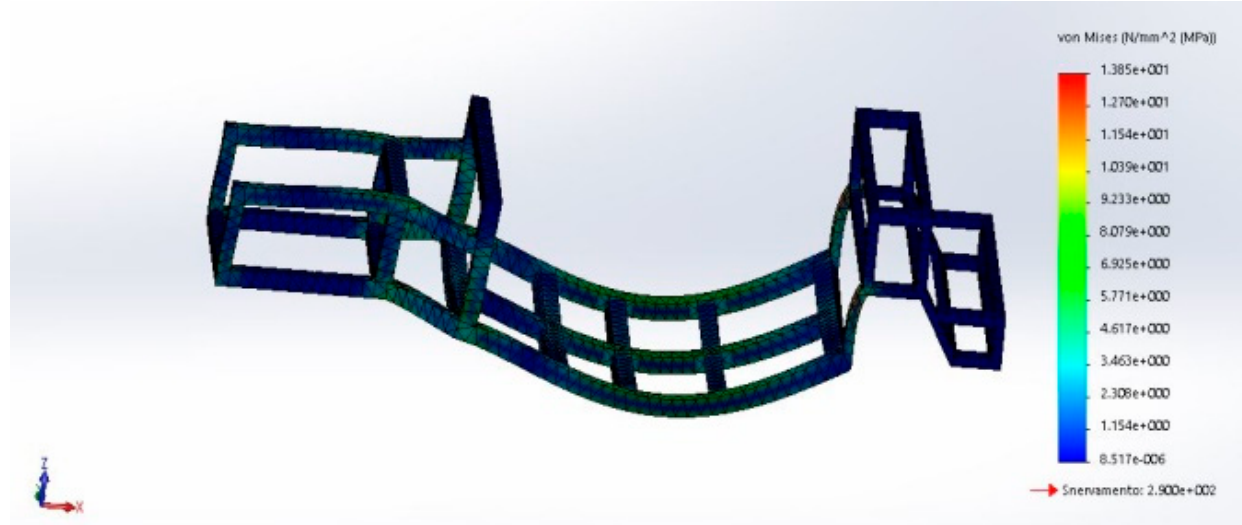

Figure 13. Maximum load: $13.8 \mathrm{MPa}$.

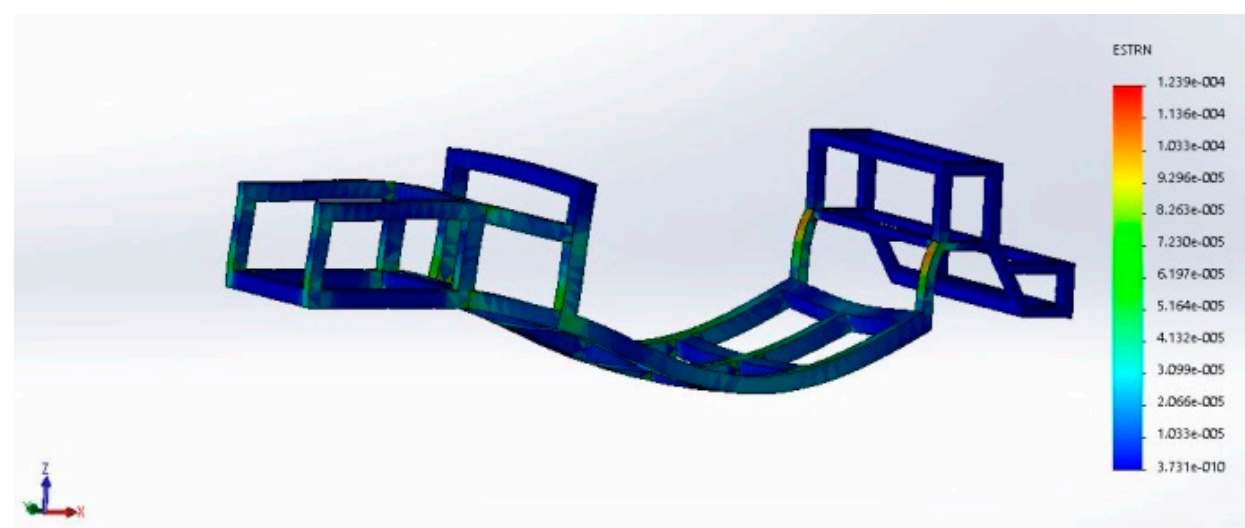

Figure 14. Maximum deformation 0.0001.

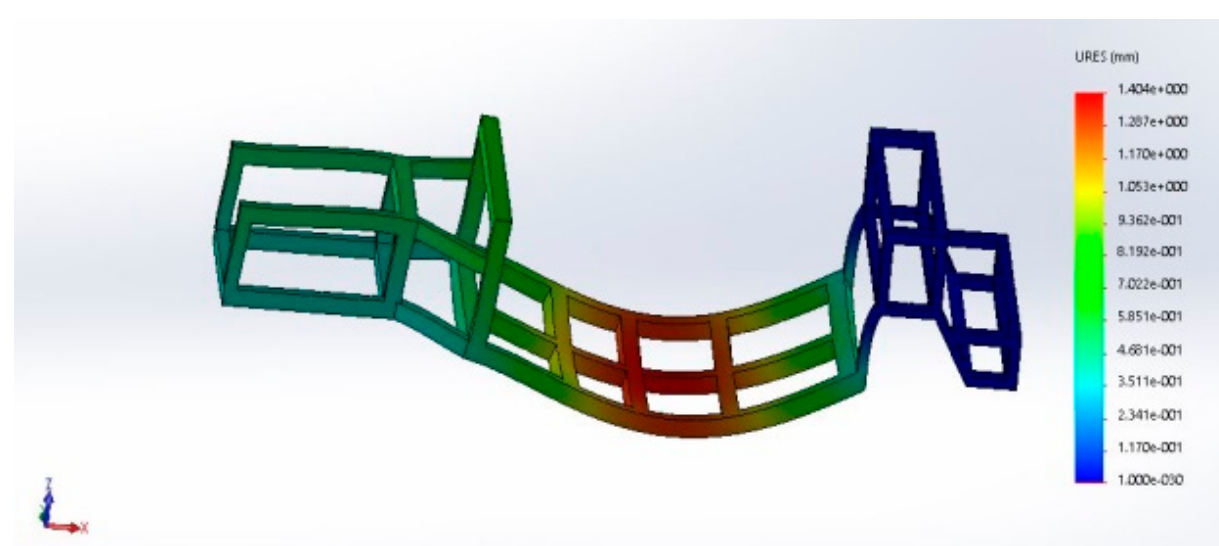

Figure 15. Maximum displacement: $1.4 \mathrm{~mm}$.

Frame with Plates

The structure (Figure 16) presents the sheets exclusively in the fundamental points, their presence in fact influences significantly the weight. The thicknesses and the position of the sheets were decided following various static analyses of which we are now going to show the final results (Figures 17-19). 


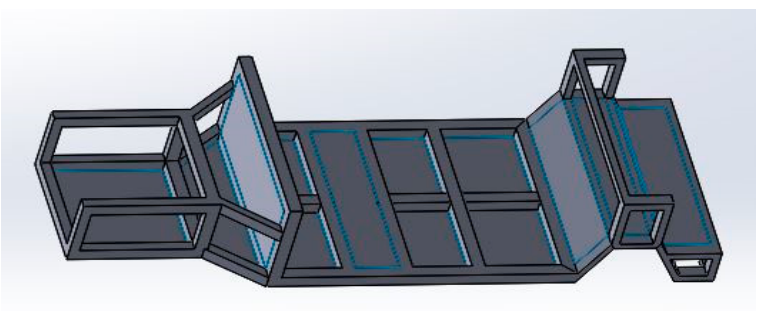

Figure 16. Frame with plates designed.

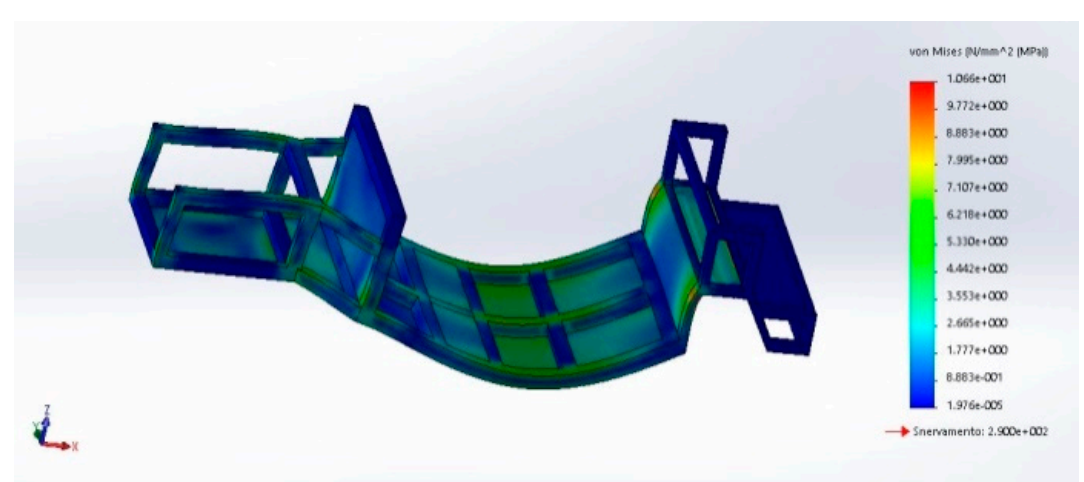

Figure 17. Maximum load: 10.6 MPa.

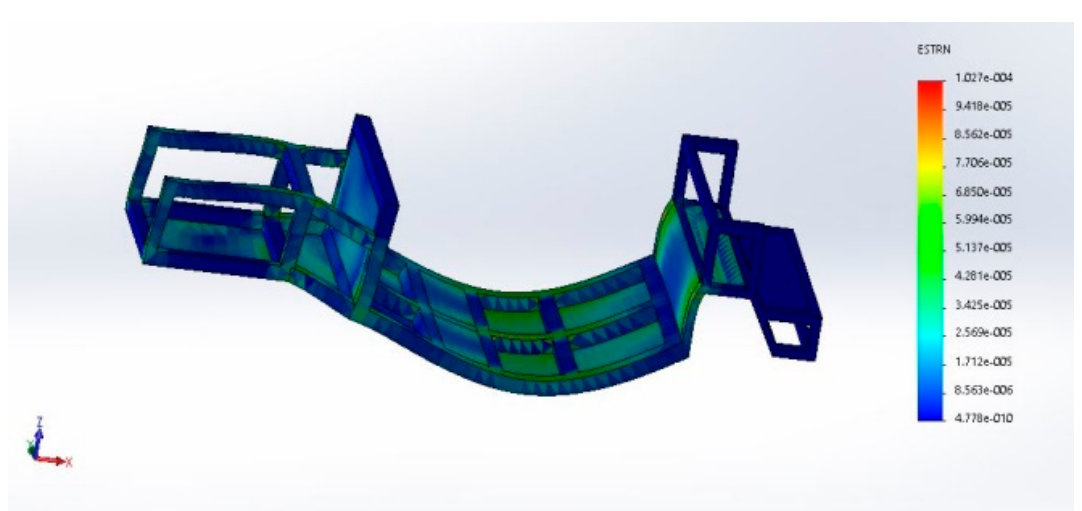

Figure 18. Maximum deformation 0.0001.

As expected, the results are better than the previous ones, all three analyses show lower maximum values. In order to perform an initial test, the thickness of the plates had been uniquely placed at $5 \mathrm{~mm}$, giving more than excellent results in all three tests. This solution gave the structure a hyper-rigidity that is not always a positive factor. For this reason, in order to minimize the weight of the car, a value of $3 \mathrm{~mm}$ was chosen for the thickness of the sheets. A separate discussion must be made for the sheet relative to the motor housing, the latter in fact showed unacceptable deformation and maximum load values, for this reason its thickness was increased to $10 \mathrm{~mm}$. For the same reason the sheet relative to the rear trunk has been designed keeping the thickness of $5 \mathrm{~mm}$.

Having thus achieved the goal in terms of resistance and weight optimization, we now complete the frame structure by inserting the uprights that will form the upper part of the car and the longitudinal tunnel that will house the crankshaft. 


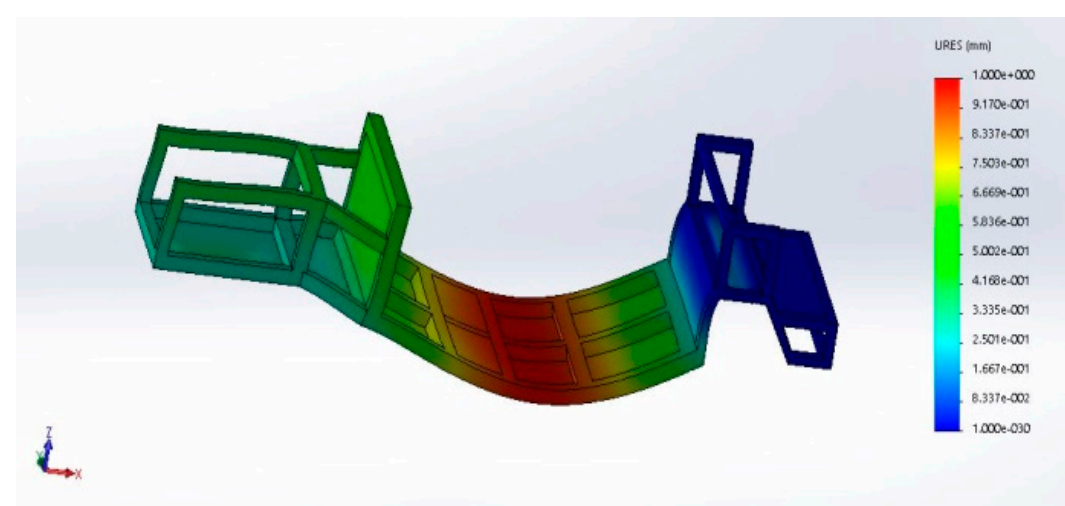

Figure 19. Maximum displacement: $1 \mathrm{~mm}$.

\section{Complete Chassis}

As anticipated, the frame was also completed in the upper part, and was then closed by inserting the imperial (Figure 20). Since the car is rear-wheel drive it was necessary to provide for the presence of a space for the passage of the crankshaft and of the wiring to the rear wheels. In the upper part of the frame have been added fittings in all the faces, in order to avoid possible concentrations of tension and also for aesthetic purposes.

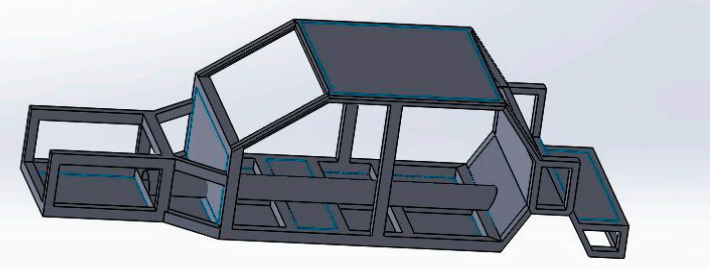

Figure 20. Complete chassis.

\section{DFSS: VALIDATE}

Once the design of the frame has been completed it is necessary to carry out the checks that show that the product has respected the objectives that had been set and that it does not present problems of any kind.

The static check is carried out one last time to observe the reaction of the complete frame to the loads and to establish which are the actual rigidity and resistance.

\subsection{Static Verification}

As expected, we get further reinforcement and stiffening of the structure, which now has excellent performance, with a maximum load of only $4.4 \mathrm{Mpa}$ and a maximum displacement of only $0.28 \mathrm{~mm}$, as shown in Figures 21-23.

The structure compared to the previous analysis improves its performance especially in the central area, where the insertion of the tunnel for the crankshaft and the closure of the structure have given greater resistance. The frame therefore satisfies the requirements of rigidity and resistance. 


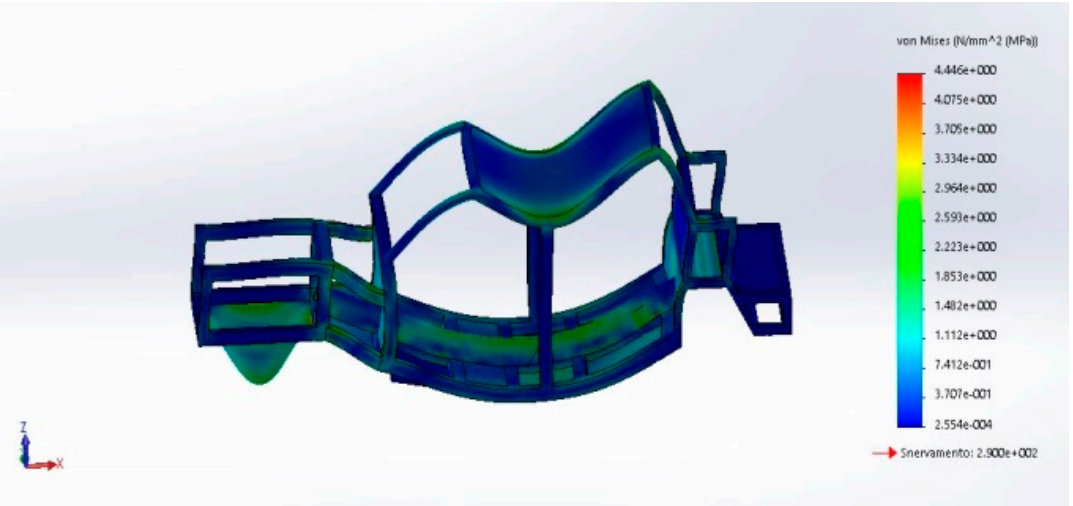

Figure 21. Maximum load: $4.4 \mathrm{MPa}$.

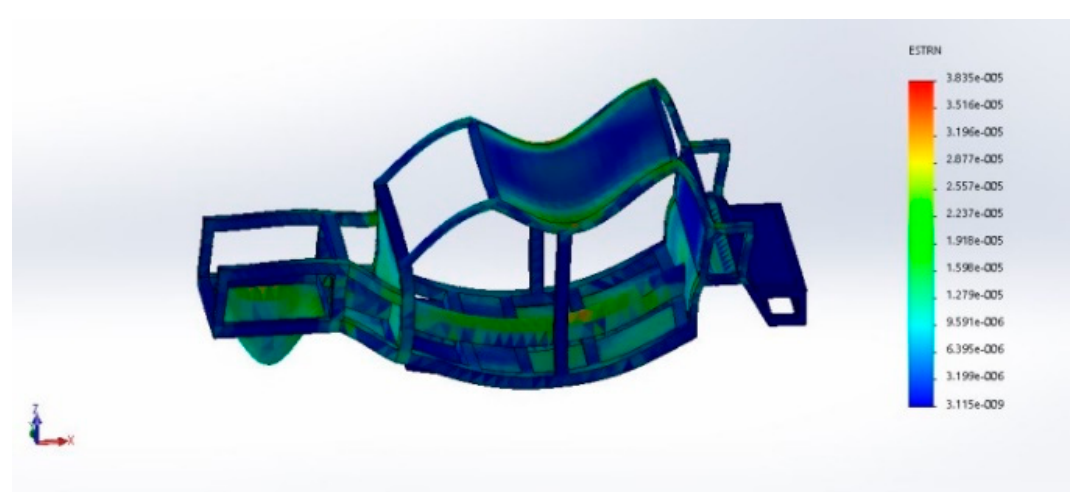

Figure 22. Maximum deformation 0.00003.

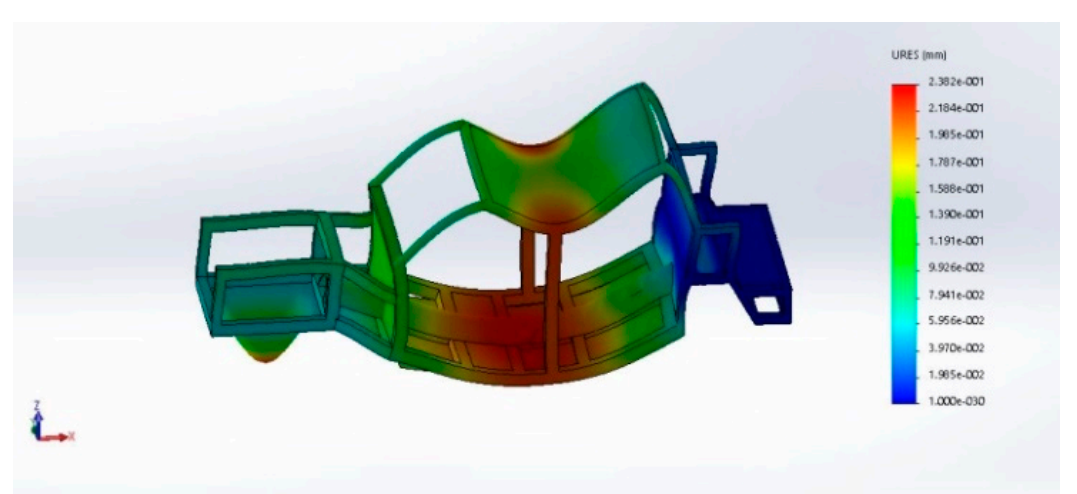

Figure 23. Maximum displacement: $0.283 \mathrm{~mm}$.

\subsection{Lay-Out Verification (VLO)}

The bulkiest and spacious components are inserted inside the car, so as to check its habitability and capacity. Thus we begin by inserting the batteries, whose seat has been inserted under the rear seats, so as not to lose space in height inside the passenger compartment (Figure 24).

After that, insert the seats in front and behind inside the passenger compartment to check if there is enough space for them (Figure 25).

Once inserted in the right positions it is necessary to evaluate the comfort of the 5 seats, for which 5 mannequins are inserted, whose dimensions are deliberately slightly oversized, so as to verify if the car is able to contain 5 adult males in comfort (Figure 26). Mannequins height: $1.82 \mathrm{~m}$.

As can be seen, from this image and from the previous one, there is enough space for 5 adult males, both in regards to the place for the feet and the width of the rear seat (Figure 27). 


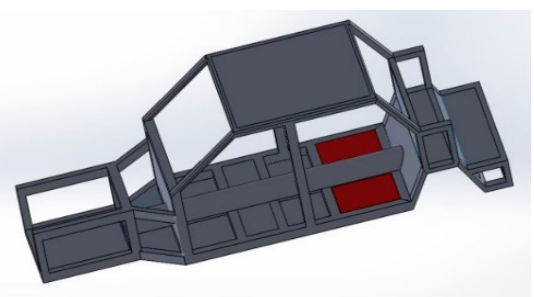

Figure 24. Verification of lay-out (VLO): battery set up.

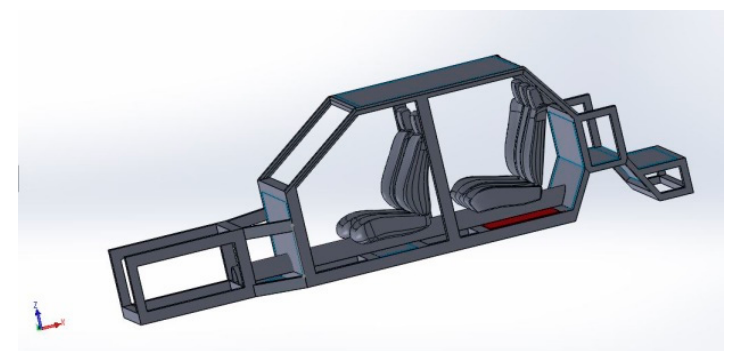

Figure 25. Verification of lay-out (VLO): seats set up.

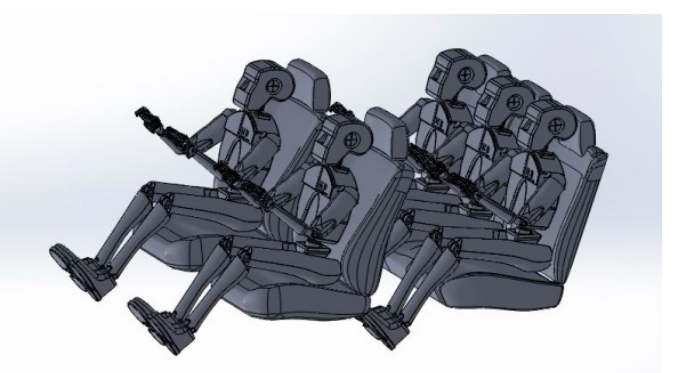

Figure 26. Verification of lay-out (VLO): five mannequins set up.

What we want to highlight with the last image is that despite the use of $1.82 \mathrm{~m}$ height mannequins, there is still a lot of space for the head inside the passenger compartment, making the car suitable also for tall passengers. Then there is the capacity of the trunk, which can comfortably hold 4 suitcases of $55 \times 40 \times 20$ (black) and two suitcases of $40 \times 30 \times 20$ (gray) size.

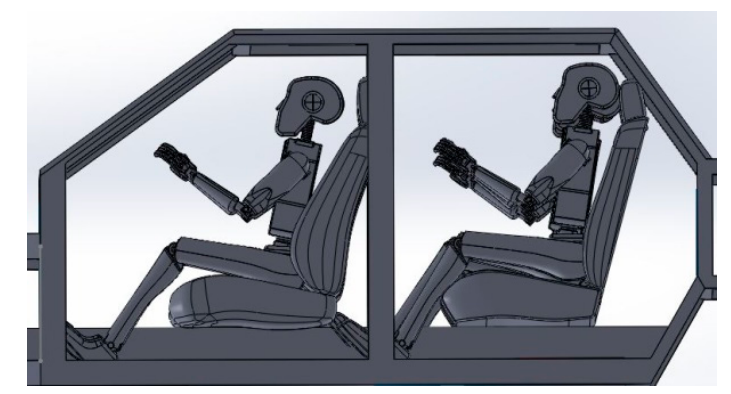

Figure 27. Verification of lay-out (VLO): five mannequins set up lateral view.

Its capacity is around $510 \mathrm{~L}$, up to more than $1200 \mathrm{~L}$ if the rear seats are lowered and the compartment separating the trunk from the passenger compartment is removed (Figure 28). 


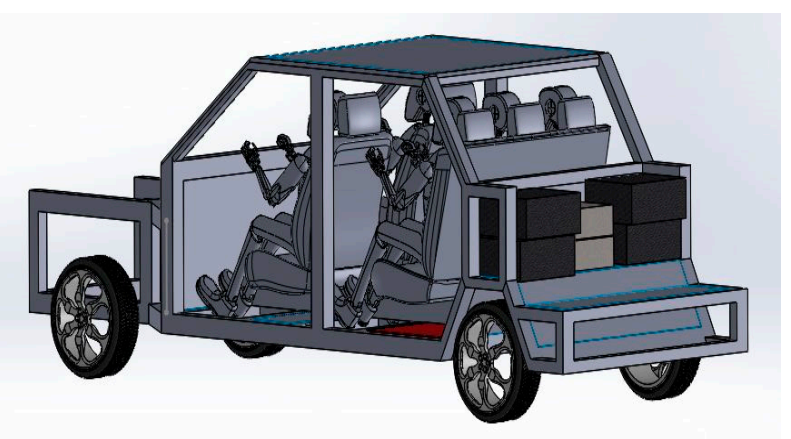

Figure 28. Verification of lay-out (VLO): trunk capacity.

Finally, all that remains is to insert the wheels in the appropriate spaces, for the designed model we consider as standard 20" rims, then insert the tires and check their correct positioning (Figure 29).

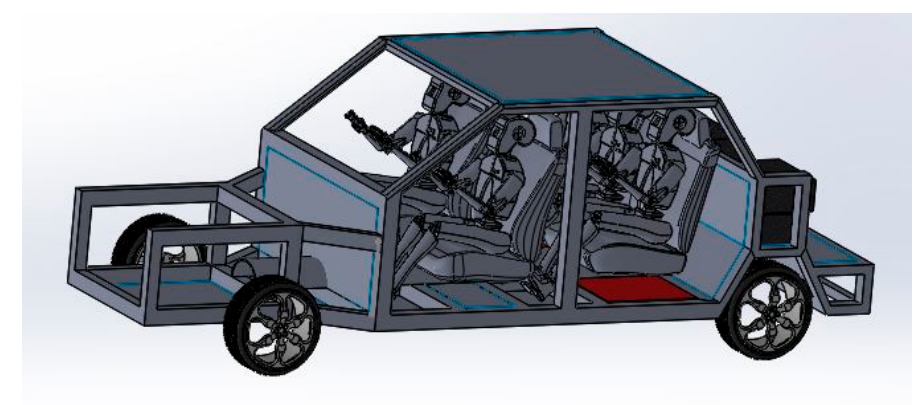

Figure 29. Verification of lay-out (VLO): wheels set up.

(Batteries remain exposed for illustrative purposes only).

\section{Discussion: Characteristics and Innovations}

Once both checks have been completed, the frame can be considered definitive.

Let us now summarize the features and innovations of this new car.

- $\quad$ The designed car is of the full Hybrid type, with a $3.5 \mathrm{~L}$ gasoline engine with rear-wheel drive that coupled to the electric motor provides a power of 345 horsepower.

- The trunk has a capacity of about $510 \mathrm{~L}$, which can become around $1200 \mathrm{~L}$, knocking down the rear seats.

- The car measures $4.90 \mathrm{~m}$ in length, 1.80 in width (considering the mirrors) and $1.48 \mathrm{~m}$ in height.

- Aluminum alloy frame: This choice made it possible to obtain a better power/weight ratio compared to all existing cars in the same segment. This allows for high performance, without penalizing consumption.

- $\quad$ Lighter frame than all currently existing cars in the same segment.

- The built frame is able to withstand high stresses, thanks to a very high stiffness and resistance.

- Consumption is very low, thanks to the heavy weight reduction and the use of large batteries, especially in cities where the electric motor does most of the work.

- Positioning the battery, its positioning under the rear seats, allows a better exploitation of the space inside the passenger compartment in terms of height.

- High comfort, the frame allows to comfortably accommodate 5 people of medium-large build.

- The price is kept low thanks to the use of not too expensive materials and the lightening of the structure. 


\section{Conclusions}

This work presented an innovative hybrid car's design, belonging to the E-segment. The Design for Six Sigma was applied in order to develop a new product, through the determination of customer and market needs and the transformation of these requests into the product generated. The result was that a new full hybrid type car was designed that presents high performances and low consumption, together with high comfort. The method adopted made it possible to develop a reliable study of possible product enhancements. Only a few constraints and limitations can be foreseen, by the translation of this conceptual study into a constructive design, linked to the material and the manufacturing process selection, which have not been specifically discussed here. Further studies could be deepened, focusing on the method application to the ambit of Logistics in the context of Industry 4.0 [34].

Author Contributions: For this research article the individual contributions have to be considered as follows: conceptualization, G.M.R.; methodology, D.F.; software, G.M.S.; data curation, G.D. All authors have read and agreed to the published version of the manuscript.

Funding: This research received no external funding.

Conflicts of Interest: The authors declare no conflict of interest.

\section{References}

1. Frizziero, L.; Donnici, G.; Francia, D.; Caligiana, G.; Gaddoni, A. Stylistic design engineering (SDE) for an innovative green vehicle following QFD and TRIZ applications. Int. J. Mech. Prod. Eng. Res. Dev. 2019, 9, 805-827.

2. Francia, D.; Caligiana, G.; Liverani, A.; Frizziero, L.; Donnici, G. PrinterCAD: A QFD and TRIZ integrated design solution for large size open moulding manufacturing. Int. J. Interact. Des. Manuf. 2018, 12, 81-94. [CrossRef]

3. Frizziero, L.; Francia, D.; Donnici, G.; Liverani, A.; Caligiana, G. Sustainable design of open molds with QFD and TRIZ combination. J. Ind. Prod. Eng. 2018, 35, 21-31. [CrossRef]

4. Donnici, G.; Frizziero, L.; Francia, D.; Liverani, A.; Caligiana, G. Increasing innovation of a new transportation means using TRIZ methodology. JP J. Heat Mass Transf. 2018, 15, 341-370. [CrossRef]

5. Caligiana, G.; Liverani, A.; Francia, D.; Frizziero, L.; Donnici, G. Integrating QFD and TRIZ for innovative design. J. Adv. Mech. Des. Syst. Manuf. 2017, 11, JAMDSM0015. [CrossRef]

6. Donnici, G.; Frizziero, L.; Francia, D.; Liverani, A.; Caligiana, G. Project of inventive ideas through a TRIZ study applied to the analysis of an innovative urban transport means. Int. J. Manuf. Mater. Mech. Eng. 2018, $8,1-24$

7. Donnici, G.; Frizziero, L.; Francia, D.; Liverani, A.; Caligiana, G. TRIZ method for innovation applied to an hoverboard. Cogent Eng. 2018, 5, 1-24. [CrossRef]

8. Kostrzewski, M. One Design Issue-Many Solutions. Different Perspectives of Design Thinking-Case Study. In Proceedings of the 13th International Conference on Knowledge Management in Organizations (KMO), Zilina, Slovakia, 6-10 August 2018; Uden, L., Hadzima, B., Ting, I.H., Eds.; Springer: Cham, Switzerland, 2018; Volume 877, pp. 179-190.

9. Francia, D.; Ponti, S.; Frizziero, L.; Liverani, A. Virtual mechanical product disassembly sequences based on disassembly order graphs and time measurement units. Appl. Sci. 2019, 9, 3638. [CrossRef]

10. Francia, D.; Liverani, A.; Donnici, G.; Frizziero, L.; Marinelli, N. A preliminary evaluation to support DFD of handcrafted product. Cogent Eng. 2019, 6, 1-20.

11. Donnici, G.; Frizziero, L.; Francia, D.; Liverani, A.; Caligiana, G. A preliminary evaluation to support DFD of handcrafted products. Int. J. Mech. Prod. Eng. Res. Dev. 2019, 9, 1033-1050.

12. Grzybowska, K.; Kostrzewski, M. The Application of Simulation Methods in the Comparative Analysis of Car Spare Parts Distribution Systems. Logist. Transp. 2016, 32, 5-16.

13. Czwajda, L.; Kosacka-Olejnik, M.; Kudelska, I.; Kostrzewski, M.; Sethanan, K.; Pitakaso, R. Application of prediction markets phenomenon as decision support instrument in vehicle recycling sector. LogForum. 2019, 15, 265-278. [CrossRef] 
14. Liverani, A.; Caligiana, G.; Frizziero, L.; Francia, D.; Donnici, G.; Dhaimini, K. Design for Six Sigma (DFSS) for additive manufacturing applied to an innovative multifunctional fan. Int. J. Interact. Des. Manuf. 2019, 13, 309-330. [CrossRef]

15. Bondioli, A. Disegno e Metodi di Progettazione Industriale a una Vettura Elettrica Innovativa; Alma Mater Studiorum-Università Di Bologna: Bologna, Italy, 2015.

16. Freddi, A. Imparare a Progettare: Principi e Metodi del Progetto Concettuale Per lo Sviluppo Della Creatività Industriale; Pitagora: Bologna, Italy, 2002. (In Italian)

17. Quattroruote.it. Available online: https://www.quattroruote.it/ (accessed on 4 December 2019).

18. La Tecnologia Ibrida Lexus. Available online: https://www.lexus.it/hybrid/\#self-charging (accessed on 4 December 2019).

19. Infiniti Auto. Available online: https://www.alvolante.it/marca/infiniti. (accessed on 4 December 2019).

20. Brochure Twin Engine. Available online: https://www.volvocars.com/it/mondo-volvo/tecnologie/drive-e/ brochure-twin-engine (accessed on 4 December 2019).

21. I Veicoli Ibridi. Available online: http://www.autosupermarket.it/magazine/i-veicoli-ibridi-facciamochiarezza. (accessed on 4 December 2019).

22. Ibrida o Elettrica? Available online: https://www.automobile.it/magazine/mobilita-sostenibile/auto-elettricaibrida-differenze-2491 (accessed on 4 December 2019).

23. Available online: https://www.autoevolution.com/news/bosch-parallel-full-hybrid-system-explained-23159. html (accessed on 4 December 2019).

24. Available online: https://www.designnews.com/automotive-0/10-and-coming-hybrids-2018 (accessed on 4 December 2019).

25. Available online: https://afdc.energy.gov/vehicles/how-do-plug-in-hybrid-electric-cars-work (accessed on 4 December 2019).

26. Piancastelli, L.; Frizziero, L.; Donnici, G. The common-rail fuel injection technique in turbocharged di-diesel-engines for aircraft applications, Asian Research Publishing Network (ARPN). J. Eng. Appl. Sci. 2014, 9, 2493-2499.

27. Piancastelli, L.; Frizziero, L. Supercharging systems in small aircraft diesel common rail engines derived from the automotive field, Asian Research Publishing Network (ARPN). J. Eng. Appl. Sci. 2015, 10, $20-26$.

28. Piancastelli, L.; Frizziero, L.; Donnici, G. Turbomatching of small aircraft diesel common rail engines derived from the automotive field, Asian Research Publishing Network (ARPN). J. Eng. Appl. Sci. 2015, 10, 172-178.

29. Piancastelli, L.; Frizziero, L.; Marcoppido, S.; Donnarumma, A.; Pezzuti, E. Fuzzy control system for recovering direction after spinning, edizioni ETS. Int. J. Heat Technol. 2011, 29, 87-93.

30. Piancastelli, L.; Gatti, A.; Frizziero, L.; Ragazzi, L.; Cremonini, M. CFD analysis of the Zimmerman's V173 stol aircraft, Asian Research Publishing Network (ARPN). J. Eng. Appl. Sci. 2015, 10, 8063-8070.

31. Croccolo, D.; De Agostinis, M.; Fini, S.; Liverani, A.; Marinelli, N.; Nisini, E.; Olmi, G. Mechanical characteristics of two environmentally friendly resins reinforced with flax fibers. Strojniski Vestnik J. Mech. Eng. 2015, 61, 227-236. [CrossRef]

32. Caligiana, G.; Liverani, A.; Francia, D.; Frizziero, L. Mechanical device with five-arms tested on service. Far East J. Electron. Commun. 2017, 17, 327-349. [CrossRef]

33. Degidi, M.; Caligiana, G.; Francia, D.; Liverani, A.; Olmi, G.; Tornabene, F. Strain gauge analysis of implant-supported, screw-retained metal frameworks: Comparison between different manufacturing technologies. Proc. Inst. Mech. Eng. Part H J. Eng. Med. 2016, 230, 840-846. [CrossRef] [PubMed]

34. Kostrzewski, M.; Varjan, P.; Gnap, J. Solutions Dedicated to Internal Logistics 4.0. In Sustainable Logistics and Production in Industry 4.0; Grzybowska, K., Awasthi, A., Sawhney, R., Eds.; EcoProduction (Environmental Issues in Logistics and Manufacturing); Springer: Cham, Switzerland, 2020.

(C) 2020 by the authors. Licensee MDPI, Basel, Switzerland. This article is an open access article distributed under the terms and conditions of the Creative Commons Attribution (CC BY) license (http://creativecommons.org/licenses/by/4.0/). 